\title{
Representative Communication: Web Site Interactivity and Distributional Path Dependence in the U.S. Congress
}

\author{
KEVIN M. ESTERLING, DAVID M. J. LAZER, \\ and MICHAEL A. NEBLO
}

\begin{abstract}
We examine the speed and extent to which members of the U.S. House of Representatives adopt emerging Web-based communication technologies. Given the growing centrality of communication for governance and the Web's growing role in effective public outreach, a rational actor approach would suggest that members of Congress should aggressively exploit online communication technology. And this should especially be true for freshman members. We test these expectations using two waves of data coded from the official Web sites of the U.S. House of Representatives, for the years 2006 and 2007. We observe that incumbents show considerable path dependence in their Web site technology adoptions, while the sites of the freshmen who won election in 2006 are largely independent of the Web designs of their corresponding predecessors. This independence does not mean, however, that freshmen are fully exploiting communication technology. Instead, the Web design practices of freshmen appear to be governed by the distribution of existing practices among incumbents, a process we label "distributional path dependence." This surprising null finding suggests that members have Web-based communication practices that are governed by informal norms socially constructed among congressional offices and that the institution is slow to adapt to emerging communication technologies.
\end{abstract}

Keywords legislative communication, legislative Web sites, U.S. Congress, path dependence, structural equation modeling

Any normative conception of accountability in democratic representation requires that legislators have the capacity to communicate directly with their constituents (Pitkin, 1967). Members in turn have strong incentives to measure up to this normative expectation (Mayhew, 1974). Because they desire reelection, members of Congress engage in ongoing

Kevin M. Esterling is Associate Professor in the Department of Political Science at the University of California, Riverside. David M. J. Lazer is Associate Professor of Political Science and Computer Science at Northeastern University. Michael A. Neblo is Assistant Professor in the Department of Political Science at Ohio State University.

This project is funded by a grant from the Digital Government Program of the National Science Foundation (Award IIS-0429452). We gratefully acknowledge the intellectual contributions from our colleagues at the Congressional Management Foundation (CMF), especially Collin Burden, Nicole Folk-Cooper, Kathy Goldschmidt, and Tim Hysom. Any opinions, findings, and conclusions or recommendations expressed in this article are those of the authors and do not necessarily reflect the views of the National Science Foundation or CMF. All replication data are available at http://tert.ucr. edu/tommy.

Address correspondence to Kevin M. Esterling, Department of Political Science, University of California, Riverside, 900 University Ave., Riverside, CA 92521, USA. E-mail: kevin.esterling@ucr.edu 
public relations outreach to inform constituents about their issue positions and to claim credit for governmental largess that flows to the district (Lipinski, 2004). Members also communicate to try to build a sense of empathy with constituents, to build trust, and to establish their expertise and credibility, communication that Fenno (1978) refers to as "presentation of self."

Recent developments in interactive Web technology have created new opportunities for enhancing communication between members and constituents when compared to both hard copy and broadcast media (Druckman, Kifer, \& Parkin, 2007). Previous studies have shown, however, that the design quality of legislative Web sites tends to lag behind those found in entertainment and e-commerce (Adler, Gent, \& Overmeyer, 1998; Burden \& Hysom, 2007; Owen, Davis, \& Strickler, 1999). In particular, members' Web sites do not typically take advantage of the interactive potential of Internet communication technologies, instead often using their Web pages simply as "electronic brochures" similar to hard copies of member newsletters (see Kamarck, 2002).

That long-serving incumbents do not make efficient or even remotely optimal use of emerging interactive technologies is perhaps not surprising. These members are likely to have developed working strategies for communicating with constituents, and a central proposition in the literature on American political development asserts the design of political institutions tends to be path dependent (Page, 2006; Pierson, 2004). Freshman members, however, typically have lower reelection margins than more senior members (Butler, 2009), and so have stronger incentives to enhance direct communication with constituents (Alvarez, 1997, p. 165). In addition, since they set up their official Web pages from scratch, freshmen presumably are not locked into a suboptimal Web site design, and so may find it easier to first reflect on how to make optimal use of information technology to best reach constituents. Like all institutional designs, Web sites are likely to be path dependent once they have been developed, but the initial design need not be.

New institutionalism theory suggests, however, that institutional norms can affect how freshmen act on these incentives in practice. The collection of offices within Congress socially construct, via institutional isomorphism (DiMaggio \& Powell, 1983), standard routines and practices for communication technology adoption (Sparrow, 2006; Suchman, 1995). Norms that have emerged from existing practices among incumbents may be taken for granted as design requirements for legislative Web sites (Bimber, 2003; Chadwick, 2006; Fountain, 2001, p. 93; Roscoe, 1999; Xenos \& Foot, 2005, p. 183). These isomorphic processes often result in suboptimal designs that are homogeneous and persistent. Even among freshmen, it may be this existing institutional normative environment, not technical best practice standards regarding the optimal use of Web-based communication technology, that governs Web site development.

To test for this, we use over-time data that code a wide array of best practice interactive attributes of the official Web sites of all House members in 2006 and in 2007, data measured both before and after a midterm election. These over-time data on Web sites allow us to assess the extent to which the design properties of incumbents' sites change from one year to another. In this election 63 seats changed hands, and this also allows us to assess the extent to which freshman Web sites differ from the sites one would expect to observe if the incumbent had stayed in office. We find that, as expected, returning incumbents demonstrate considerable path dependence from year to year in the interactive qualities of their Web sites. In contrast, the interactive qualities of a typical freshman's Web site are almost completely unrelated to the qualities of her or his predecessor's site. This independence is generally true for all freshman sites taken together, as well as specifically for seats that did not change parties and for seats where the incumbent left office voluntarily. Among 
freshmen, then, we do not observe the ordinary sequential path dependence that is typically conceived of in the literature on American political development (Page, 2006), where the actions of individuals are "locked in" by their own past institutional circumstances (Pierson, 2004).

But saying that freshmen are not locked into a particular Web site design does not mean that freshmen necessarily exploit anything near the full communication potential the medium offers. Instead, we find that the design qualities of freshman Web sites are simply independent draws from the existing distribution of Web site practices among returning incumbents. The existing distribution of sites among incumbents, rather than site best practice standards, appears to serve as the normative institutional environment for freshmen as they design their Web sites from scratch. Freshmen appear to be locked into a form of path dependence in which the existing distribution of practices serves as the institutional normative environment conditioning site design. We label this process, where the practices of incoming actors are governed by a distribution that preexists within an institution, "distributional path dependence."1 This process resembles an information cascade, where individual members are led to neglect this objectively crucial aspect of their communication strategy.

\section{Enacting Interactive Technology and “Distributional” Path Dependence}

As Schaffner (2006) notes, members benefit from their efforts in representing a district only when constituents actually know what the member claims to have accomplished (see also Lipinski, 2004; Mayhew, 1974). Survey results show that, beginning in the mid-2000s, citizens now consider members' official Web sites an important source of political information compared to the traditional media. For example, the 2006 Cooperative Congressional Election Study survey (http://dvn.iq.harvard.edu/dvn/dv/cces) asked respondents to indicate all of the media sources they would use to discover where their member of Congress stood on issues. By far, the modal choice was the member's official Web site, which was the choice of $72 \%$ of respondents. In contrast, only $36 \%$ of respondents indicated they would find this information by calling or writing the office directly, $19 \%$ from TV news, $7 \%$ from TV talk shows, $8 \%$ from radio news, $13 \%$ from radio talk shows, and $20 \%$ from newspapers and magazines. In addition, $37 \%$ of respondents said they received political news and information from the Web sites of elected officials.

In this context, a rational actor approach would argue that all members have powerful incentives to make optimal use of Web-based communication technology, and especially those who desire reelection. As Alvarez (1997) and Bartels (1986) note, voters tend to be risk averse, and hence uncertainty about their member decreases their level of support. Schaffner (2006) finds that incumbents who garner relatively more newspaper coverage are more likely to gain constituents' votes. Since citizens are turning more and more to members' official Web sites for information, one could expect that an informative and well-designed site could especially further members' reelection prospects, as well as their ability to govern effectively while in office.

In this article, we assess the quality of what Stromer-Galley (2000) labels the "media interactivity" of legislators' official Web sites, that is, the "interactive nature of the medium itself" (p. 118). ${ }^{2}$ With media interactivity, users are able to control the medium to locate information, through hyperlinks, search engines, downloading capacities, audio, and video. Media interactivity on official legislative Web sites enables "one-stop" information portals 
in what Jane Fountain (2001) calls the "virtual state" (p. 4), where citizens can gain information regarding their legislators that is of most interest and importance to them, at low search costs and with minimal gatekeeping (Garson, 2004, p. 4).

While all members have incentives to communicate effectively via their official Web sites with their constituents, freshmen often have the greatest strategic incentive to increase the media interactivity of their sites. Freshmen tend to expect stronger challenges than long-serving incumbents and so have relatively higher incentives to reduce the uncertainty of undecided voters (Adler et al., 1998, p. 587; Alvarez, 1997; Druckman et al., 2007, pp. 429-430; see also Herrnson, Stokes-Brown, \& Hindman, 2007). ${ }^{3}$ While all incumbents typically have advantages over challengers (Erikson, 1971; Gelman \& King, 1990), a number of studies have shown that the incumbent advantage is lower for freshmen running in their first reelection than for more senior members. For example, using a regression discontinuity design and data on House elections between 1946 and 2004, Butler (2009) demonstrates that the margin of victory for freshmen is about 2.3 percentage points lower than for nonfreshmen (see also Alford \& Hibbing, 1981; Canes-Wrone, Brady, \& Cogan, 2002, pp. 133, 136; Dawes \& Bacot, 1998). ${ }^{4}$

In addition to having this greater strategic incentive to exploit communication technology, freshmen also should find it less costly to adopt technical best practice standards compared to more senior incumbents. Since freshmen do not have sunk costs invested, they are less likely to be locked into a particular Web site design (Pierson, 2000). Conditional on having to build a Web site from scratch, the marginal cost of attending to best practices should be quite low. One can make an analogy to developing countries having better wireless networks than developed countries, as the former have the chance to plan as they set up infrastructure from scratch (Pentland, Fletcher, \& Hasson, 2004). Thus, freshmen have greater incentives as well as fewer barriers to consult best practice standards (Burden \& Hysom, 2007) as they design their sites from scratch.

Politicians often lack the technical background knowledge to make optimal or efficient use of new technology, however, or even to assess the risk that might be associated with technical innovations (Dawes, Bloniarz, \& Kelly, 1999, p. 20; Druckman et al., 2007, p. 429; Ferber, Foltz, \& Pugliese, 2005, p. 144; Fountain, 2001, p. 88; Owen et al., 1999, p. 27). Working within the framework of new institutionalism, Sparrow (2006) argues that communication practices are instead socially constructed within interorganizational fields through processes of institutional isomorphism. Institutions create normative environments for what communication practices are considered appropriate, professional, or legitimate (Fountain, 2001); it is these within-institution norms, rather than technical best practice standards, that determine how technology is used by the institutions' members (DiMaggio \& Powell, 1983; Lieberman, 2002; Xenos \& Foot, 2005). ${ }^{5}$ Given the path dependence of institutional practices, technology typically develops faster than organizations can accommodate. As a result, all members of Congress, even those with relatively unsafe seats, might only use a very limited range of functionality in the communication technologies available to them (Dawes et al., 1999, p. 21; Fountain, 2001, p. 88). This new institutional perspective suggests that all members, even those who are electorally vulnerable, will be slow to adopt emerging communication technology.

\section{Data}

We assess these expectations using data coded from the official Web sites of members of the U.S. House of Representatives. The coding occurred in two waves, one wave in 2006 and one in 2007. A general election intervened between these two time points that 
resulted in 63 seats changing hands. The two cross-sections in this study allow us to test the year-to-year dynamics of incumbent Web sites, and whether freshman sites are similar to or different from what we would expect to observe if the corresponding incumbent had remained in office.

Web technology is changing rapidly, and so we do not present our analyses as a journalistic account of current Web practices within Congress. Examining the dynamics of Web practices surrounding a recent election is important, however, as the data allow for a case study of how legislators adapt to technology at a time when the objective technology itself is undergoing rapid change (Bimber, 2003, p. 8). As we note above, surveys show that by 2006, members' own constituents expressed demands for informative official Web sites. Our data allow us to test the extent to which members respond to these demands.

For our data, we use the Congressional Management Foundation (CMF) codings of all offical House Web sites, completed for each congressional office in each of the two years. In the summers of 2006 and 2007, teams of trained coders at CMF accessed and coded each official Web site based on nearly 100 operational criteria (see Johnson, 2004; Owen et al., 1999). CMF identified and defined the criteria using a number of sources regarding best practice standards for legislative Web sites, specifically by asking focus groups of citizens to spend time on a sample of sites, interviews, and surveys with office staff and citizens and by conducting Web industry research (Burden \& Hysom, 2007). ${ }^{6}$

The coding for the 27 variables we use for this study and the instructions given to the coders are listed in the Appendix. The descriptive statistics for the coded variables are listed in Table 1. Table 1 partitions the coded variables into three groups, where in each group the items measure an important latent quality of legislative Web sites: the quality of the issue information (Druckman, Hennessy, Kifer, \& Parkin, 2009), the quality of constituency services (Adler et al., 1998), and the quality of the online technology of the site (Druckman et al., 2007). These items measure the quality of the media interactivity of the site on these three dimensions. The issue and constituents dimensions assess the quality of the information citizens typically seek when interacting with legislative Web sites. The technology dimension measures the presence and overall quality of the media interactive communication technology on the site. For purposes of this article, we confine our definition of the "quality" of a Web site's media interactivity to these three dimensions.

The data set includes seven items that measure the quality of issue information on each site. These are coder ratings of the quality of information regarding national, state, and local issues and issues of special importance to the member; the presence of rationales that help explain the member's voting decisions; and a discussion of current events. We also include two measures of how up to date the information is on the Web site, an objective measure of whether the issue information covers issues from the current Congress, and a subjective rating of the overall timeliness of the information available on the site.

We use nine items to measure the overall quality of constituency services on the Web site. These include coders' rating of the quality of casework FAQ answers, the presence of information on how to initiate casework with the member's office, whether the site includes an online casework initiation form, and the presence of links to federal agencies and to FirstGov.gov (now www.usa.gov). We also include measures of the presence of information regarding internships in the member's office, how to be nominated to a military academy, how to acquire a flag that has flown over the Capitol building, and about local district resources and services.

For items measuring the technical quality of each Web site, we include measures of whether or not the site contains audio, video, has a text-only option, a blog, an RSS feed, 
Table 1

Descriptive statistics

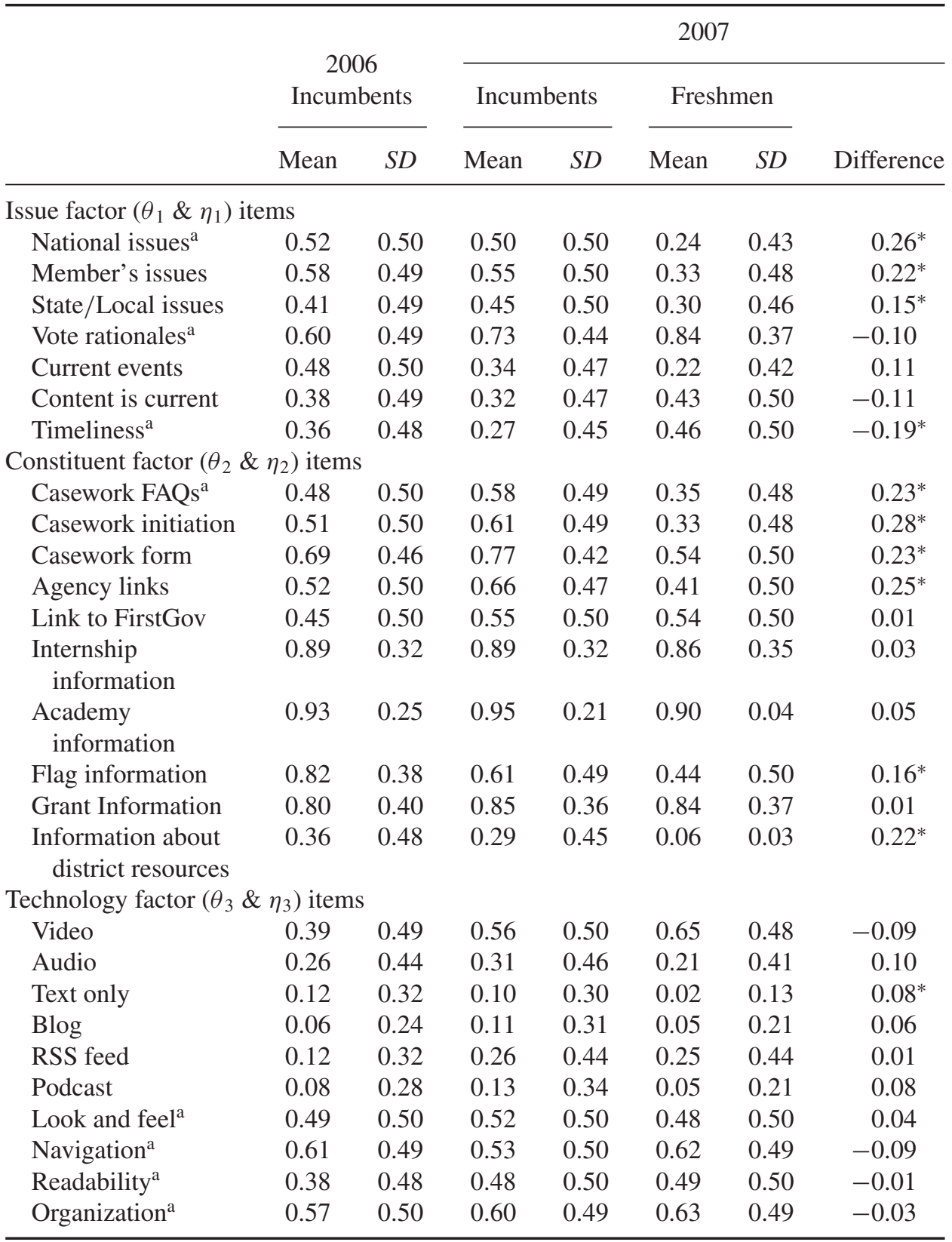

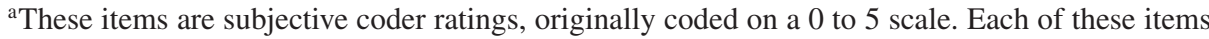
has been dichotomized in a manner that maximizes the variance of the dichotomous variable; see the Appendix and Note 7 for specifics. Number of incumbents in $2006=538$; number of incumbents in $2007=474$; number of freshmen in $2007=63$.

${ }^{*} p<.05$. 
and podcast capabilities. We also include subjective measures of the overall look and feel of the Web site, its navigability, its readability, and its organization.

Each item in Table 1 is dichotomous, ${ }^{7}$ so the cell entries are the percentages of members' Web sites that either possessed the item or were rated on the high end of a subjective scale. The column labeled 2006 includes all sites from the first wave of coding, the year before the election. The columns for 2007 report the percentages for incumbents and freshmen separately for the second wave of coding. The final column reports the differences in percentages for each item between incumbents and freshmen in 2007. With the exception of timeliness, all items where there is a statistically significant difference show incumbents have a higher percentage than freshmen. The result for timeliness is perhaps trivial since any information on a freshman's site must be new. These descriptive results suggest that freshmen overall tend not to be especially effective at exploiting Web communication technology, a point we test more formally in the statistical model.

\section{Statistical Model}

Like many concepts in social science, it is difficult if not impossible to reliably capture the "quality" of Web site media interactivity with any single measure. Any specific measure would not capture the richness of what we mean by Web site media interactive quality, and any general measure would be too subjective to be reliable in statistical tests.

In this article we rely on structural equation models that estimate the quality of each Web site's media interactivity as a set of three latent variables, one each for issue quality, constituent services quality, and technology quality in each of the two years. The full model is diagrammed in Figure 1. The full set of equations for this model is set out in the Appendix. In the diagram, the ovals indicate latent variables, the boxes contain observed indicator variables, straight arrows assign variables to equations (or equivalently, indicate regression coefficients), and curved arrows indicate estimated correlation parameters. The structural equation model allows some latent variables to be regressed on other latent variables (Bollen, 1989).

A latent variable is an unobserved variable, and hence the value for each latent variable for each Web site is a parameter to be estimated. The point estimate for each site's latent variable value serves as the point estimate of the (latent) quality score for the site along the corresponding dimension. ${ }^{8}$ Because this point estimate is a parameter to be estimated, we are able to make inferences about the latent quality of each member's Web site under different assumptions. For example, in addition to the scores a freshman actually received given her or his observed Web site in 2007, we can estimate what the site would have scored on each of the three latent distributions in 2007 under the assumption that the previous incumbent had instead retained her or his seat. In addition, the set of these point estimates, taken as a whole, defines a distribution for each latent variable, similar to how ordinary observed variables are governed by a distribution. As a result, we can compare the distribution of each latent variable across subgroups of the sample, such as between freshmen in 2007 and incumbents in 2007.

In the structural equation model, we regress each of the 2007 latent variables on each of the 2006 latent variables. The straight arrows connecting the latent variables in Figure 1 represent the structural parameters of these regressions. These parameters may be interpreted as ordinary regression coefficients. If we set the data for freshmen in 2007 to missing, these structural parameters test for the degree to which the technical quality of 


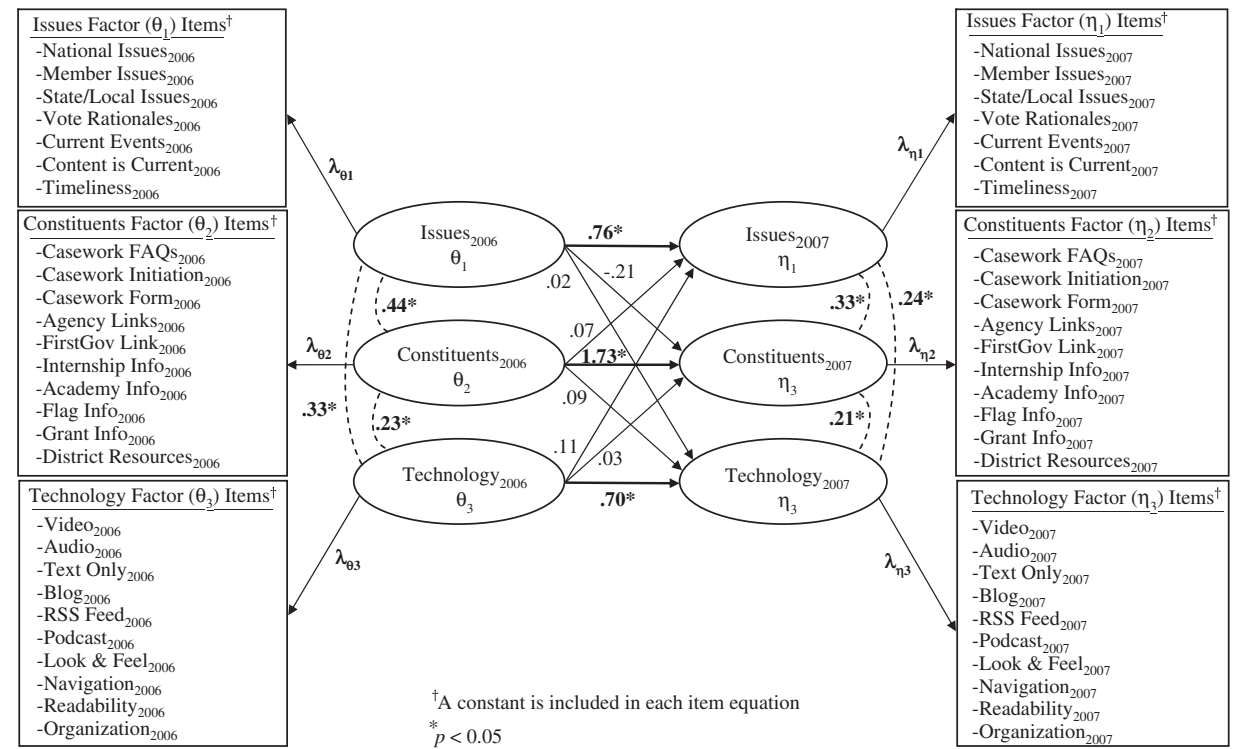

Figure 1. Web site quality structural equation model.

a member's Web site in one year can be predicted from the technical quality of the same member's site in the previous year. ${ }^{9}$

We estimate the distribution for each latent variable using an item response theory model (Trier \& Jackman, 2008), where each latent variable is measured with the set of coded items listed in each corresponding box of Figure 1, and each $\lambda$ is a vector of parameters. ${ }^{10}$ In all, three latent variable distributions are estimated using a total of 27 items, in each of the two years. We estimate the correlations among the latent variables within a given year, indicated by the dashed curved arrows, by assuming the three latent variables themselves are multivariate normally distributed, each with a mean of zero vectors and a variance matrix to be estimated. Since the covariances among the latent variables are estimated in the model, we are able to assess how the latent variables relate to each other. In particular, positive correlations among the latent variables imply that the interactive quality of a Web site itself is a latent property, in that members who tend to do well on one dimension tend to do well on all. ${ }^{11}$

In the analysis, we use the model depicted in Figure 1 as well as several restricted versions of the model. We first estimate the full model, but while setting each 2007 freshman's Web site coded scores to missing data to test for the consistency of incumbents' sites from 2006 to 2007. In this regression, we estimate the structural coefficients where latent variables are regressed on other latent variables; we also use this model to impute the missing values on the latent variables for the 2007 freshmen as a way to infer what we would have observed on the incumbent's Web site if she had instead retained her or his seat. Second, we reestimate the same model but this time also setting a random sample of 43 of the 2007 incumbent Web site codings to missing. This second model allows us to observe how well the model predicts returning incumbents' observed 2007 sites compared to the first model's attempts to predict freshmen's observed 2007 sites. Third, we estimate the model using all data from 2007 (without conditioning on data from 2006) in order to place incumbents and freshmen in 2007 on the same latent variable scales. This model 
allows us to compare the distribution of scores between incumbents in 2007 and freshmen in 2007 for each of the three dimensions.

\section{Results}

We first present the results showing our success in predicting nonfreshman incumbents' 2007 media interactive Web site scores using their 2006 scores. These results strongly suggest that returning incumbents are locked into this crucial and increasingly important component of their communication strategy, in the normal sense of path dependence as envisioned in the institutions literature (Pierson, 2000). Next, we show that the media interactive qualities of freshman Web sites are essentially independent of the qualities of their predecessors, indicating that freshman Web site designs are not locked in by the qualities of their predecessors' sites. We then show that the distribution of the qualities of freshman Web sites is nearly identical to the distribution of incumbent sites, indicating that freshmen are locked into a distributional path dependence where their Web site designs are governed by the existing distribution of practices within the institution. Finally, we examine whether there are some specific Web site items where incumbents and freshmen tend to differ, as a way to identify the sources of any discrepancies between incumbent and freshman quality distributions.

\section{Ordinary Path Dependence Among Returning Incumbents}

We begin by considering the extent to which the Web sites of returning incumbents changed between 2006 and 2007. The extent to which Web sites remain static indicates that incumbents are locked into a site design or display the ordinary path dependence that typically is envisioned in the institutions literature. Figure 1 presents the results of the regressions of the latent variables from 2007 on those from 2006, displayed on the straight arrows connecting the latent variables in the figure.

These regressions among the latent variables help to test two separate sets of hypotheses. First, they test whether a latent variable from 2007 can be predicted from the same latent variable measured from the 2006 data. If one were to array all of the regression coefficients in a matrix, where the rows and columns have identical labels, these on-diagonal coefficients would fall on the diagonal. If these coefficients are of the magnitude that high scores in one year often result in high scores in the second year, this would be evidence that some incumbents serve as standard setters for the institution. If these coefficients are positive but of low magnitude, this would suggest that both high and low scoring Web sites tend to regress toward the mean. Second, these regressions test whether the other latent variables have an independent effect on Web quality in 2007. Label these coefficients the off-diagonal elements. The off-diagonal elements would be large and significant if Web site quality had a dynamic feedback effect, for example, if a member's site having especially good technical features in one year caused the member's office to revamp the issue information the following year.

The results summarized in Figure 1 show the Web sites of most of the returning incumbents changed very little in this period. For each latent variable in 2007, the offdiagonal elements are not significant, suggesting that the Web site quality dimensions themselves do not have any dynamic feedback properties. For each of the three latent variables for 2007, only the coefficients for the same latent variable from 2006 are predictive, that is, the on-diagonal coefficients. But these coefficients are not of the magnitude that 
the previous year's Web site wholly determines the current year's site. Instead, assuming a member is one standard deviation above the mean for any of the latent variables in $2006,{ }^{12}$ given each of the on-diagonal estimated regression coefficients, one would expect the same member to be about a half of a standard deviation above the mean in the same dimension in 2007. This suggests that members are regressing to the mean on all three dimensions and are not typically improving their sites from year to year. ${ }^{13}$ In addition, we note modest but statistically significant correlations between the latent variables for both years, ranging from 0.21 to 0.44 (all with $p<.05$ ). This suggests that to a modest extent, Web sites that score high on one dimension tend to score higher on the other two, but the relationship is rather weak.

In summary, among incumbents we observe modest dependence between the latent variables, a lack of dynamic feedback among the qualities of the Web sites, and the tendency for incumbents to regress to the mean on each of the three quality dimensions.

These results suggest that the distribution of Web site design practices among incumbents is not dynamic and apparently not prone to change. This can be seen graphically in Figure 2. To generate the results in this figure, we first set the coding of a random sample of 43 incumbents in 2007 to missing data and used the 2006 data and the model of Figure 1 to impute the coding for each of the 27 items as well as the latent variable values for each of these missing incumbents. In Figure 2, we plot the imputed latent variable scores for each of these missing incumbents with their actual score estimated in the model where their observed data are included. For each dimension, we find a strong correlation between the imputed and the actual values. The correlation between the imputed and the actual score for each of the frames in Figure 2 is $\rho \geq 0.72$, with each $p<.001$.

One might argue that this persistence in year-to-year Web site designs among incumbents is due to electoral or strategic decisions about optimal communication practices, not to path dependence. Members might take care to tailor their Web site designs to district interests and voter demands. To test this, we correlated the 2006 quality scores for each member with a wide array of district characteristics and the electoral circumstances the member finds him- or herself in $^{14}$ and found that only one of the 16 district variables were correlated with the point estimates for any of the three quality score variables (members from safer seats had lower quality constituent service factor scores); this overall pattern is one that could be observed by chance. ${ }^{15}$ Using data taken from the CMF 2004 House Staff Employment Study (CMF, 2004), we do find that all three factor scores
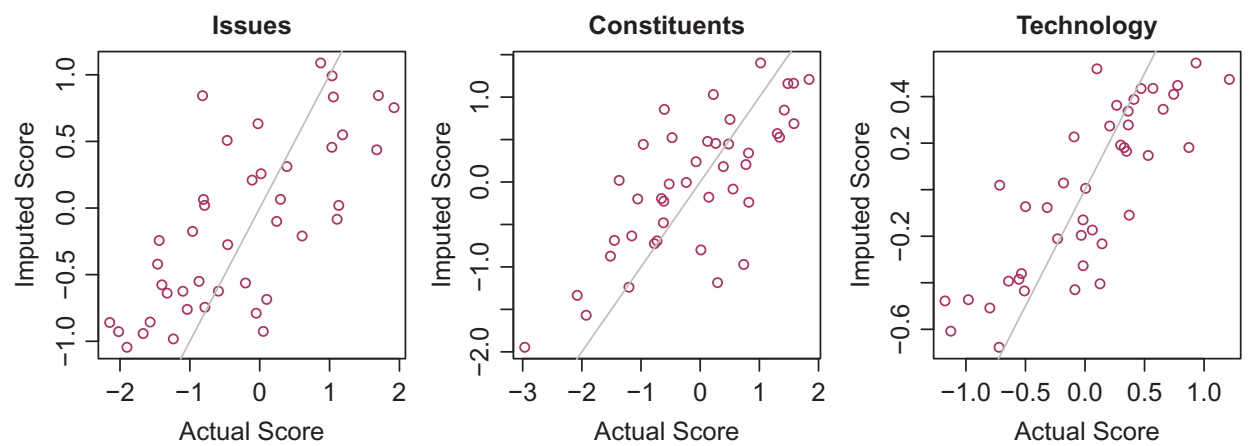

Figure 2. Imputed and actual expected quality scores for incumbents (posterior means; color figure available online). 
are jointly correlated with management practices within the member's office. For example, the total number of staff employed in the office is positively correlated with all three factors, and the decision to contract systems administration to outside vendors is negatively correlated. ${ }^{16}$ These correlations suggest that Web site quality is largely idiosyncratic to the member's office management practices.

The picture that emerges from these results is not one of existing incumbents who serve as the vanguard of technology adoption. While there are certainly some members who make great efforts to improve their Web sites, these members statistically are very much the exception to the rule. Instead, most incumbents who make efforts one year to develop a high-quality Web site typically regress toward the mean the following year. Remarkably, members' efforts to manage online information bear no systematic relation to factors that should drive their strategic incentives to do so. This is quite a striking null finding.

\section{Freshman Web Design Practices Are Independent of Predecessors}

The results presented in Figures 1 and 2 are strongly consistent with the proposition that returning incumbents are locked into a Web site design. There is little evidence to suggest that incumbents are quick to adopt new best practices for site design. Freshmen, however, may be a different story. Since freshmen set up their Web sites from scratch, it is possible, indeed sensible, that freshmen would consult best practices standards as they design their new sites.

There are two possible reasons, however, to expect that freshmen may be locked into a Web site design even before they begin their new job. First, it is possible that freshmen will base the design of their new Web site on the existing design of the outgoing incumbent's site. Given the costs and effort required to design a site from scratch, it might be sensible for freshmen to emulate the former incumbent's site, a site that presumably would be already well tailored to the stylistic and substantive communication demands of the district. Second, it is possible that unobserved variables that vary across congressional districts explain much of the actual variation in Web site quality. If district variables are driving site design, even if a freshman did not consider the incumbent's site in her or his own design, the two sites still would appear similar.

Figure 3 helps to assess whether freshman Web sites resemble the sites that one would expect to observe if the corresponding incumbents had remained in office. Recall from Figures 1 and 2 that returning incumbent Web sites in 2007 are well predicted by the design of their sites in 2006. As a result, we are reasonably able to predict what would have been the 2007 design of the sites of the incumbents who did not retain their seats with a high degree of confidence simply by estimating the full model in Figure 1 and setting all of the 2007 coded data for freshmen to missing. We also estimate the actual values for each of the three latent variables in 2007 using a model that includes the observed data for freshmen in 2007 without conditioning on the data and latent variables from 2006 (or identically, constrains all structural coefficients among the latent variables to zero). Using these two models, we generate both imputed and actual Web quality scores for each freshman in 2007.

Figure 3 graphs the relationship between these imputed and actual scores for each of the three latent variables. It is apparent from each panel in this figure that there is little if any relationship between the design of freshman Web sites and the design of the predecessors' sites. First consider this relationship among all freshmen taken as a group, that is, ignoring the differentiation among symbols in the graph. None of these unconditional correlations are statistically significant. The unconditional correlation for the technology 

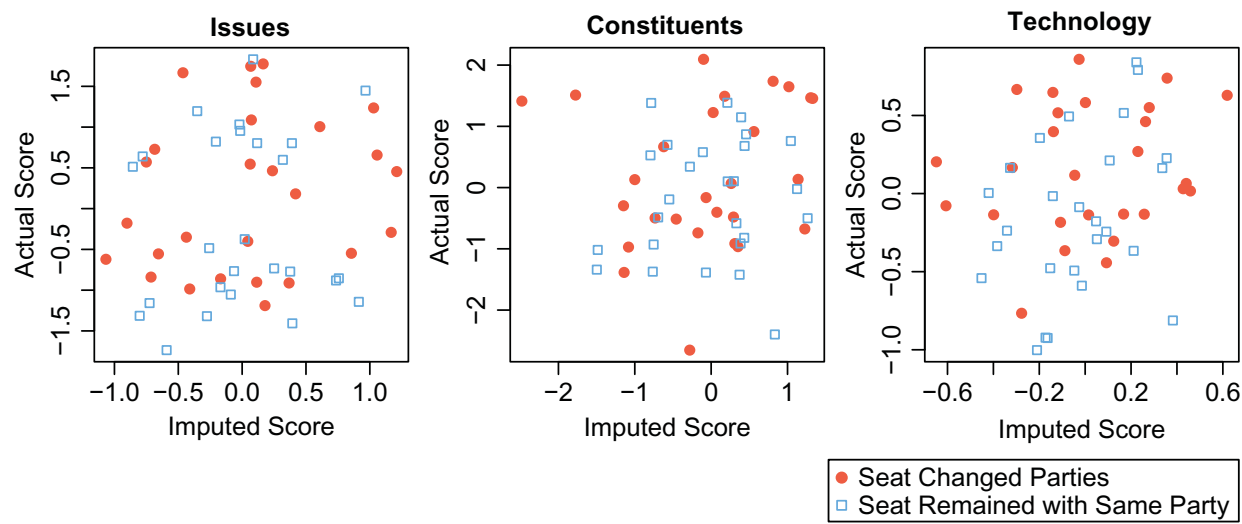

Figure 3. Imputed and actual expected quality scores, by party change (posterior means; color figure available online).

latent variable approaches conventional levels for significance, $\rho=0.24, p=.08$, but substantively this correlation is small. The absence of correlations here is in stark contrast to those for incumbents, shown in Figure 2.

Next, consider conditioning on whether or not the seat changed parties, shown by the different symbols in each panel of the figure. Here, one might assume that when a seat remains in the same party, a freshman might have special incentives to base her or his Web site on that of her or his predecessor. But the conditional correlations among those seats that do not change parties, as well as among those that do change parties, are not statistically significant. Again, the correlation for the technology latent variable comes the closest, $\rho=0.30, p=.13$, when conditioned on the seat remaining in the same party.

Figure 4 considers this same question, but now using a finer grain to distinguish why the incumbent did not retain her seat. On the one hand, independent of party, one might expect a freshman purposefully to choose to ignore the Web site of a member who lost
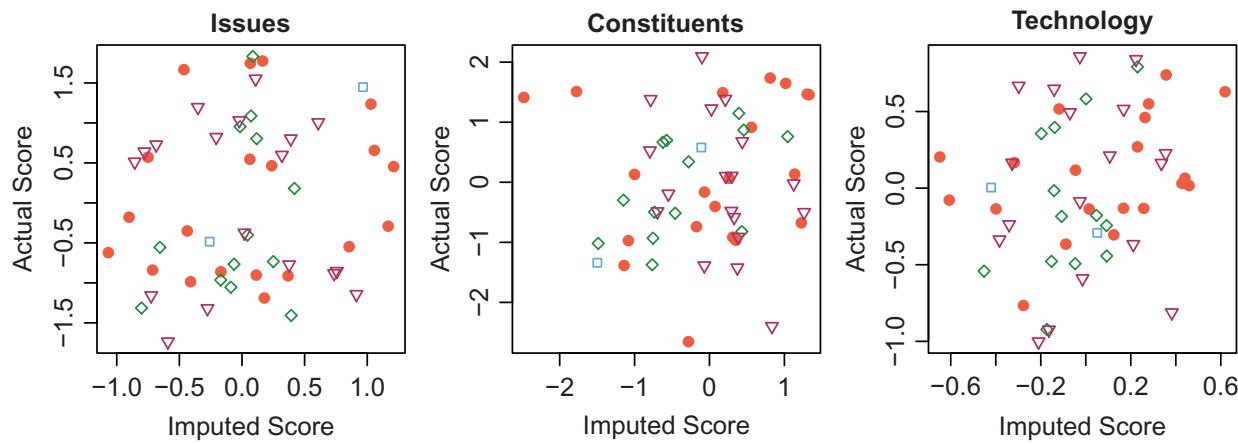

- Defeated Incumbent in General Election

- Defeated Incumbent in Primary

$\diamond$ Incumbent Retired

$\nabla$ Incumbent Ran for Higher Office

Figure 4. Imputed and actual expected quality scores, by incumbent's outcome (posterior means; color figure available online). 
the election, reasoning that it might be time for renewal. On the other hand, a site might still retain value to a freshman if the incumbent had been successful in office but chose to step down anyway, either through retirement or, perhaps even more so, if the ambitious incumbent chose to run for higher office.

Figure 4 shows that freshman Web sites are largely independent of their predecessors' sites, irrespective of the reason the incumbent left office. The unconditional correlations in each panel are identical to the ones in Figure 3. Among the conditional correlations, there is a significant correlation only for the constituent service quality score for the condition where incumbents retired, $\rho=0.57, p=.04$. In addition, none of the pairwise $t$ tests for the difference of means between each condition (within each frame) are statistically significant.

Note that Figures 2 through 4 compare point estimates for each quality dimension. The Bayesian model estimates a full posterior distribution for each quality score for each member, reflecting our uncertainty in the location of these point estimates. Because of this, we can test whether the distributions of the predicted and actual quality scores are distinct, separately for the freshman sample and for the random sample of returning incumbents who were set to missing. In this test, for each of these samples, we take the predicted score (the vertical axis in each figure) as fixed at the point estimate, and the imputed score (the horizontal axis) as an estimate, and calculate the percentage of Web sites where the imputed point estimates are more than one standard deviation away from the predicted value. For the freshman sample, by this measure we find that $53 \%$ of the distributions are distinct for the issues dimension, $43 \%$ for the constituents dimension, and 36\% for the technology dimension. The corresponding statistics for the incumbents' sample are 24\%, 19\%, and $10 \%$. That is, the freshman Web sites are far more independent than incumbents', with each of the differences in percentages statistically distinct at $p<.01$.

Taken together, Figures 3 and 4 show that there is very little dependence between the design of freshman Web sites and that of their predecessors, in strong contrast to the dependence we observe among returning incumbents. These results rule out two possibilities. First, freshmen do not appear to cut and paste from their predecessors' site to reduce their start up costs. Freshmen do begin effectively from scratch. Second, this also confirms that district-level variables are not important drivers of Web site quality.

\section{Distributional Path Dependence Among Freshmen}

The results of the previous section show very clearly that freshmen indeed begin their terms with a clean slate, an HTML tabula rasa. Knowing this, one might expect that freshmen would typically consult with best practice standards (Burden \& Hysom, 2007). To the extent this is true, we would observe freshmen as a group having higher scores on the latent variable measures compared to the distribution of scores among returning incumbents. Freshman sites would be above average in the quality scales.

However, to say that freshmen are not locked into the Web site designs of their predecessors is not necessarily to say that freshmen use Web site communication technology optimally. Those elected to public office typically do not possess extensive technical skills, and hence they may not know how to direct their staff to make optimal use of Web communication technology or even consider the need to on their own accord. Instead of consulting best practice standards, it is possible that freshmen simply look to the existing practice standards that have developed within the institution, or equivalently, hire the same Web design vendors used by their peers. Current design practices create a normative context that defines what Web site designs are appropriate, strategically useful, less risky, and 
legitimate (DiMaggio \& Powell, 1983; Suchman, 1995). We have already demonstrated, though, that current incumbents do not typically engage in dynamic, transformative practices in Web site design. If freshmen look to the existing distribution of design practices, then the distribution of freshman quality scores on the three dimensions should be similar to the distributions among incumbents. This information cascade process can lead individual members to overlook the potential for this crucial mode of communication.

We can test for the equality of the three quality score distributions between freshmen and incumbents in 2007 using the estimates from the model that does not condition 2007 estimates on 2006 data and that includes the observed 2007 codings for all members, including freshmen. Recall that the model estimates a quality score for each latent variable for each legislator in the data set. ${ }^{17}$ Including freshmen and incumbents in the same model places all members' scores in the same scale for each quality dimension. In this analysis, we simply compare the distributions of these scores, along each dimension, between the freshman and incumbent subgroups.

Figure 5 presents the results graphically, where each panel provides a quantilequantile (QQ) plot comparing the freshman and incumbent empirical distributions for the three quality score dimensions. The two distributions are empirically identical if the dots tend to lie on the gray line. If the dots tend to lie below the gray line, then the freshman distribution has a higher mode than incumbents, and if they lie above, then incumbents have a higher mode. The graphs also report a formal statistical test, the KomolgorovSmirnov test for the equality of the two distributions. Note that two of these distributions are nearly identical, the quality of issue information and the technical qualities of the Web site. In the middle panel, the distributions for the constituent service quality scores are statistically different, but it is the incumbents who tend to have a higher average score, not freshmen.

These results strongly suggest that freshmen do not make effective use of communication technology. If anything, freshmen in 2007 tended to have worse quality Web sites compared to incumbents. One might wonder then if this is typically true. Recall that there are only 63 freshmen in the sample, a size small enough to have distinct distributions through sampling error, or more accurately, through the idiosyncrasies of this particular freshman class. To test for this, we reran the model using only the 2006 data, comparing those who were freshmen (in their second year of their first term) to those who had served at least one term before the 2004 election.
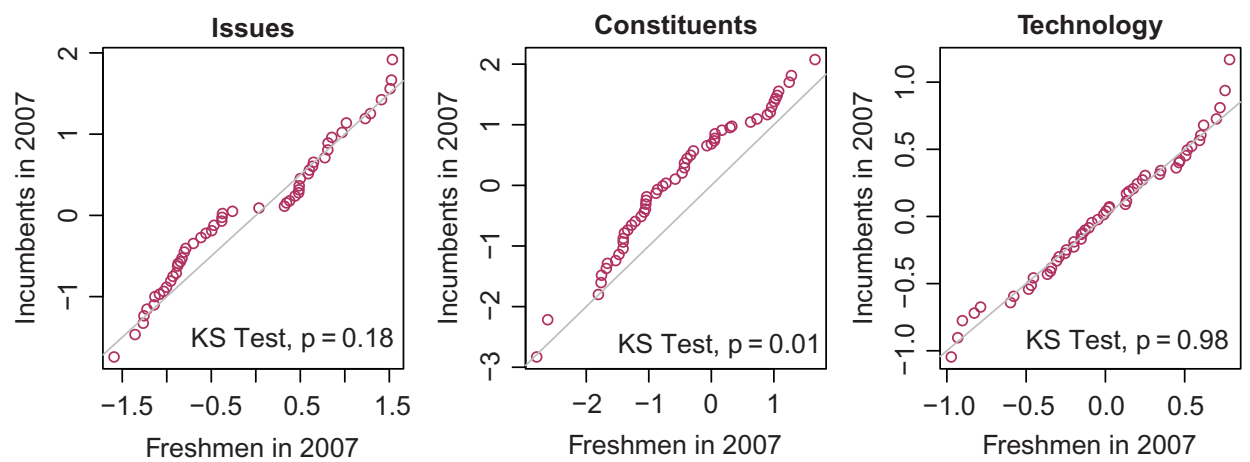

Figure 5. QQ plots comparing expected quality score distributions between freshmen and incumbents, 2007 (color figure available online). 

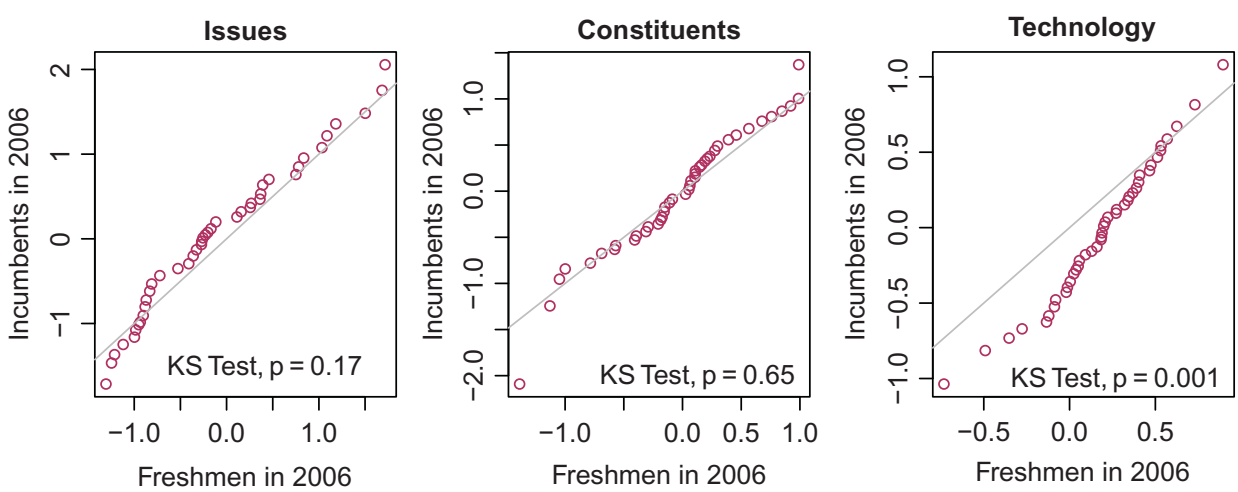

Figure 6. QQ plots comparing expected quality score distributions between freshmen and incumbents, 2006 (color figure available online).

Figure 6 presents the results of this analysis. This figure shows that these freshmen (elected first in 2004) also tend to have very similar Web site quality scores as returning incumbents (in 2004) for the issues dimension and, this time, the constituents dimension. The final panel shows that the class of 2004 freshmen tend to have a higher mode for the technology dimension. When compared to the results in Figure 5, several interesting findings emerge. First, in four out of six distributional tests, the distribution of freshman scores is nearly identical to that of incumbents. Second, there are some freshman classes who tend to have better designs than incumbents, and some that do worse. But this difference appears to be driven by the idiosyncrasies of the members who compose the freshman class, and the results as a whole rule out any notion that freshmen, by virtue of their freshman status, are efficiently exploiting communication technology, even though they have strong incentives and low marginal costs to do so. Third, the results show the importance of evaluating data from multiple years. Indeed, if researchers were to conduct this distributional analysis using only the 2006 data, one might be tempted to conclude erroneously that freshmen are especially effective at adopting new communication technologies.

\section{Item Analysis}

In the above analyses, we compared the distributions of Web site quality scores between freshmen and incumbents, both to show that freshman site designs in 2007 are independent of their predecessors' designs and that freshmen in 2007 have similar quality scores on the three dimensions as incumbents in 2007. But these quality scores themselves are estimated from a set of items, and it is possible that freshmen and incumbents tend to emphasize different sets of items, which taken together yield similar overall scores. The analogy would be if we had used a linear index to construct the scores. In such an index, if an incumbent used half of the items, and a freshman used the other half, then the linear index would give them each a similar score even though the designs are dramatically different. In this section, we report several analyses that focus on the individual items rather than on the latent variable distributions.

We first consider the independence of freshman Web site designs from their predecessors using the 27 individual items. We conducted 27 cross-tabulations, testing whether the presence of each code on the incumbent's 2006 Web site predicts its presence on freshmen's 2007 site. The answer is a very clear "no." Only one out of the 27 tables had a 
statistically significant prediction beyond chance, or just the number of significant differences one would expect to observe if the process were truly independent. Descriptively, 14 out of the 27 tables showed that there was a positive relationship between the items, and 13 showed negative relationships.

We next consider whether freshmen in 2007 are statistically more likely to use any of the features or codes compared to incumbents in 2007. The final two columns of Table 1 show that, with the exception of timeliness (which freshmen should score higher on by default) and vote rationales, incumbents tend to have higher probabilities of having each item on their Web site. That incumbents tend to have a high rate of including items on the constituency service scale is reflected in the higher mode in their constituent quality score distribution in Figure 5.

\section{Alternative Explanations}

These results demonstrate that congressional Web site designs, for both freshmen and incumbents, are governed by a common distribution. We argue that it is the distribution of current Web sites within the chamber that creates this normative environment, and that the normative environment itself conditions the designs of legislative sites. One could imagine countering that the common distribution of Web site designs we observe is not causal but instead is merely a by-product that similar types of people are elected to congressional offices, and the distribution of Web site designs is merely driven by the type of people who are elected or by district-level variables.

We reject this argument, and we do so in two ways. First, as noted above, we observe no local-level dependence between a freshman's Web site and the previous incumbent's site. But if the Web site designs were driven by the types of candidates who are elected, or by district-level variables, we should observe a good deal of dependence at the local level, since district-level variables are constant and since members elected from the same district are typically more similar to each other compared to members from other districts.

Second, using a model of spatial dependence (Congdon, 2003, chapter 7), we also find no spatial dependence among adjacent congressional districts (results not reported). Again, since members from adjacent districts are similar to each other, and since districtlevel variables are strongly correlated at this level, if Web site designs were driven by the types of members or local-level variables, we should observe dependence at this level. We argue instead that Web site designs are governed by the normative environment of the chamber, whether the design is driven by staff or by the vendors that members hire to design their sites. ${ }^{18}$

\section{Conclusion}

We show that freshmen are not locked into suboptimal Web site design. Freshmen must attend to building a Web site, and so they have a low marginal cost to build a good one. Given that they tend to be electorally vulnerable, their incentives to do so should be strong. But in practice freshman Web site designs are governed by the distribution of sites defined by existing institutional practices. That is, among freshmen we do not observe "process" path dependence that is typically conceived of in the literature on American political development, where an individual is locked in by her or his own past actions or the actions of her or his immediate predecessors (Pierson, 2000). Instead we observe a "distributional" path 
dependence where freshman Web site designs are simply draws from the status quo distribution of existing practices. The distribution of existing Web site communication practices appears to define what legislative site designs are acceptable or legitimate.

Typically, through the logic of path dependence among incumbent members, the normative environment governing institutional practices is slow to change. To say that norms change slowly is not to say that they cannot change (see Lieberman, 2002), or that institutions cannot adapt to technological developments (Fountain, 2001, p. 12). When legislators do adopt new technologies, for whatever reasons, the practices of the new adopters can disrupt existing normative standards and enable new communication practice standards to emerge (Bimber, 2003, p. 13; Chadwick, 2006, p. 3). For example, Xenos and Foot (2005, p. 183) note legislative campaign Web site designs have emerged as a well-defined genre, where omitting basic issue or biographical information stands out as a noticeable omission. Web sites in the House of Representatives overall have improved since the mid-1990s. There does not seem to be any institutional drive, however, that leads individual members to make the most out of Web-based communication technology. Indeed, institutional norms might be functioning as a kind of misleading information cascade that obscures the individual incentives that freshman members have to attend to building a high-quality Web-based communication platform. One might hope that freshmen would reflect on and incorporate best practices, since in the long run these Web sites could serve to transform and update institutional norms (Bohman, 2004, p. 51; Shane, 2004, p. 73); we do not find evidence of this. ${ }^{19}$

The overall picture of Web site technology adoption that emerges from these analyses is of an institution that is in a suboptimal equilibrium with respect to an effective or efficient use of Web communication technology. Incumbents are locked into Web site designs based on their own prior years' designs. Those incumbent members who tend to score well in one year tend to regress to the mean the next. Freshmen are not locked into a specific design based on their predecessor, but they tend to be inward looking toward existing institutional practices when establishing a Web site from scratch, rather than outward looking to technical best practice standards. Our results suggest a type of governmental failure, or a suboptimal institutional design that does not effectively serve constituents of the 21st century. Given the enormous and growing importance of communication and communication technology in politics, it is perhaps even more curious that these results suggest a failure of individual rationality on the part of freshmen, and of members more generally.

\section{Notes}

1. This distinction resembles the one Page (2006) makes between "path-dependent" and "phat-dependent" processes. "Distributional path dependence" expands on the conception of a phatdependent process but where the argument of the outcome function is a cross-sectional distribution rather than a sequential history.

2. We do not evaluate members' adoption of what Stromer-Galley (2000, p. 117) calls "human interactive" technology, more recently referred to as the Web 2.0. Human interactivity requires the capacity for interaction between two or more people through a computer interface, where each is equally able to share and receive information. Legislators currently do not make extensive use of this form of technology (Owen et al., 1999; Stromer-Galley, 2000), mostly out of concern that this form of interactivity can take the Web site "off message" (Druckman et al, 2007, p. 433; Kamarck, 2002; Stromer-Galley, 2000, p. 125).

3. Druckman et al. (2007, p. 436) find that candidate Web sites include more media interactive features and more up-to-date information as races get tighter. 
4. There are several likely reasons for freshmen's diminished advantage. First, freshmen members typically have worse committee assignments and less seniority, making it more difficult for them to engage in constituency service and to direct funding to projects in the district (Cox \& Morgenstern, 1993; King, 1991). Second, Goodliffe (2004) finds that the longer a member is in office, the larger her or his campaign warchest, and that the larger the warchest, the lower the quality of the challenger (see also Epstein \& Zemsky, 1995; Levitt \& Wolfram, 1997). Butler (2009, p. 127) notes that freshman incumbents are 25 percentage points more likely to face a quality challenger than more senior incumbents. As a result, freshmen also typically raise more campaign contributions than nonfreshmen (Cox \& Magar, 1999; Grier \& Munger, 1993). (Butler [2009, p. 126] finds no difference between freshmen and nonfreshmen in fundraising, but this is likely a reflection of the local effect estimate in his regression discontinuity design; nonfreshman incumbents who barely won their previous election likely have the same added incentives for fundraising as their freshmen counterparts.)

5. An expectation that the underlying, hard-wired programming of developed Web technology determines the content or forms of Web sites within political institutions would require a belief in "technological determinism," where the objective or material properties of the technology itself cause institutional change independent of human agency or the state of current institutional practice (see Fountain, 2001, p. 84; Chadwick, 2006, p. 18).

6 . Because the data come from two different years, we must assess intercoder reliability within each year as well as across the two years. There were a total of eight coders involved in each year. Each CMF coder evaluated 10 common Web sites in each of the two years. Coders received extensive training and then evaluated all Web sites in a randomized order, and did not know which $10 \mathrm{Web}$ sites were the common Web sites. The error rates within each year were very low across the items, ranging from as low as $8.2 \%$ to as high as $15.0 \%$, when one would expect about a $50 \%$ error rate by chance. To assess over-time reliability, two of the coders happened to participate in each year's coding effort. In the 2007 coding, we asked these two coders to code an additional 10 Web sites that were archived from 2006. The error rates never exceeded $20 \%$ across the items. On only one item (out of over 100 items) did there appear to be a drift in the standard for evaluation between the two years, where both coders rated one item (vote rationales) slightly higher in 2006 than in 2007. Overall, the withinyear and over-time reliability of these data appear to be good, reflecting the extensive training each coder received.

7. Most of the items measure the presence or absence of a feature, and so have a dichotomous measure. The items that require a subjective rating were measured on a 0 to 5 scale. We dichotomize these ratings to reduce the degree of subjective error in their measure. Dichotomizing the variables also reduces the complexity of the model, given the large number of outcome equations in the model and hence the large number of unconstrained threshold parameters required to model ordinal data. In each case, we dichotomized the variable in a way that maximized the dichotomized variable's variance, keeping the same coding for both years.

8. This quality score point estimate is directly analogous to traditional factor scores.

9. The values of missing data are imputed in the model as missing at random when conditioned on the previous year's data (Tanner \& Wong, 1987); the units with missing data are not dropped as in ordinary regression analysis.

10. In an item response theory model, each latent variable is estimated using a set of equations. In each equation, the item serves as an outcome variable and is regressed on a constant and the unobserved latent variable multiplied by an unconstrained factor coefficient via a probit link function. For identification, the factor coefficient for one of the items must be set to one, and this in turn scales the corresponding latent variable to the empirical variance of the item.

11. We use Bayesian MCMC estimation via WinBUGS (Spiegelhalter, Thomas, Best, \& Gilks, 1996). We assign at priors for all effect parameters, a Wishart prior for each variance matrix, and positive uniform priors for the item factor coefficients to constrain each to be positive. We estimated three chains for the posterior distributions, which after a burn in period were stationary by the Brooks, Gelman, and Rubin diagnostic (Gelman \& Rubin, 1992). 
12. The standard deviations are as follows: issues 2006 (0.855), issues 2007 (1.161), constituents 2006 (0.487), constituents 2007 (1.536), technology 2006 (0.285), technology 2007 (0.320).

13. For identification, the model constrains the means of each latent variable to be the same, zero, for both years, which assumes the mean of the distribution between the two years for each pair of latent variables to be equal. This assumption would be problematic if all Web sites improved from year to year. To test for this year to year shift, we were able to conduct an overtime analysis since a coder in 2007 recoded an archived version of the highest rated site in 2006, for Javier Becerra (D$\mathrm{CA}$ ), and we reran the analysis including this extra "bridge" observation. We found only eight Web sites in 2007 scored higher than the 2006 Becerra site, or only $1.8 \%$ of the sample. CMF also coded all Senate Web sites (although we do not use the Senate data in this study), and we conducted an identical over-time test for Senate Web sites. In the Senate, the highest rated Web site from 2006 would also have been the highest rated site in 2007. Thus, we find very little evidence of noticeable year-to-year improvement in the quality of these legislative Web sites, and hence the common mean assumption is reasonable.

14. These district variables are the percentage White, median household income, percentage holding white-collar jobs, percentage holding blue-collar jobs, percentage over 64, percentage under 18, percentage college educated, and percentage rural (all taken from the Census); the percentage voting for Bush in 2004, the member's age, the member's margin of election in 2006, and the member's age (taken from public records); and the percentage registered to vote in 2006, the member's summer 2006 approval rating, the percentage of voters intending to turn out in the fall 2006 election, the average level of political interest, and the frequency of Internet use among residents in the district (taken from the 2006 CCES, http://dvn.iq.harvard.edu/dvn/dv/cces).

15. Neither member nor district characteristics should have much of an effect on adoption, since all members, whether representing urban or rural, high or low socioeconomic-status, etc. district, desire to communicate well with constituents. As a result, we do not expect observed covariates to explain much of the variation, and indeed, the literature finds that district characteristics have little effect (Adler et al., 1998, p. 591; Cooper, 2004, p. 352; Druckman et al., 2007; Druckman et al., 2009, 17; Ferber et al., 2005, p. 147). We also demonstrate this below when we show that freshman Web sites are nearly independent of their predecessors' sites. If Web site design were heavily conditioned on district characteristics, then we would observe a dependence between freshmen and their predecessors' sites driven by unobserved district level variables. Web adoption is instead more idiosyncratic and personal, and likely reflects the heterogeneity in members' management practices and interest in Web technologies.

16. Interestingly, the salary paid to the press secretary is negatively related to all three factors, which suggests that Web sites might serve as a substitute for other forms of press contacts.

17. The model is fully Bayesian, so technically, the model estimates a distribution for each legislator's value for each of the three latent variables. In this analysis, we take the mean of each of the three distributions as the point estimates for each legislator.

18. A third possibility includes a normative environment outside of the chamber, although no other research has suggested that members look to external Web sites for their standards, and it is not clear even what external Web sites those would be.

19. There have been several efforts at the federal level at revamping governmental technical standards, including Newt Gingrich's efforts to modernize the House Web presence through the Cyber Congress Project and an expanded role for the House Information Resources Office (Adler et al., 1998, p. 586), as well as the Clinton administration's 1993 National Performance Review directed by Al Gore (Fountain, 2001, p. 18).

\section{References}

Adler, E., Gent, C. E., \& Overmeyer, C. B. (1998). The home style homepage: Legislator use of the World Wide Web for constituency contact. Legislative Studies Quarterly, 23, 585-595.

Alford, J. R., \& Hibbing, J. R. (1981). Increasing incumbency advantage in the House. Journal of Politics, 43, 1042-1061. 
Alvarez, R. M. (1997). Information and elections. Ann Arbor: University of Michigan Press.

Bartels, L. M. (1986). Issue voting under uncertainty: An empirical test. American Journal of Political Science, 30, 709-728.

Bimber, B. (2003). Information and American democracy: Technology in the evolution of political power. New York, NY: Cambridge University Press.

Bohman, J. (2004). Expanding dialogue: The Internet, public sphere and transnational democracy. In P. M. Shane (Ed.), Democracy online: The prospects for political renewal through the Internet (pp. 47-61). New York, NY: Routledge.

Bollen, K. A. (1989). Structural equations with latent variables. New York, NY: Wiley.

Burden, C., \& Hysom, T. (2007). 2007 Gold Mouse Report: Lessons from the best Web sites on Capitol Hill. Washington, DC: Congressional Management Foundation.

Butler, D. M. (2009). A regression discontinuity design analysis of the incumbency advantage and tenure in the U.S. House. Electoral Studies, 28, 123-128.

Canes-Wrone, B., Brady, D. W., \& Cogan, J. F. (2002). Out of step, out of office: Electoral accountability and House members' voting. American Political Science Review, 96, 127-140.

Chadwick, A. (2006). Internet politics: State, citizens, and new communications technologies. New York, NY: Oxford University Press.

Congdon, P. (2003). Applied Bayesian modelling. Hoboken, NJ: John Wiley.

Congressional Management Foundation (CMF). (2004). 2004 House Staff Employment Study. Washington, DC: U.S. House of Representatives, Chief Administrative Officer.

Cooper, C. A. (2004). Internet use in the state legislature: A research note. Social Science Computer Review, 22, 347-354.

Cox, G. W., \& Magar, E. (1999). How much is majority status in the U.S. Congress worth? American Political Science Review, 93, 299-309.

Cox, G. W., \& Morgenstern, S. (1993). The increasing advantage of incumbency in the U.S. states. Legislative Studies Quarterly, 18, 495-514.

Dawes, R. A., \& Bacot, A. H. (1998). Electoral career patterns and incumbency advantage in the U.S. House of Representatives. Legislative Studies Quarterly, 23, 575-583.

Dawes, S. S., Bloniarz, P. A., \& Kelly, K. L. (1999). Some assembly required: Building a digital government for the 21 st century. Albany, NY: Center for Technology in Government.

DiMaggio, P. J., \& Powell, W. W. (1983). The iron cage revisited-Institutional isomorphism and collective rationality in organizational fields. American Sociological Review, 48, 147-160.

Druckman, J. N., Hennessy, C. L., Kifer, M. J., \& Parkin, M. (2009). Issue engagement on congressional Web Sites, 2002-2006. Social Science Computer Review, 27, 1-21.

Druckman, J. N., Kifer, M. K., \& Parkin, M. (2007). The technological development of congressional candidate Websites: How and why candidates use Web innovations. Social Science Computer Review, 25, 425-442.

Epstein, D., \& Zemsky, P. (1995). Money talks: Deterring quality challengers in congressional elections. American Political Science Review, 89, 295-308.

Erikson, R. S. (1971). The advantage of incumbency in congressional elections. Polity, 3, 395-405.

Fenno, R. F. (1978). Homestyle: House members in their districts. Boston, MA: Little, Brown.

Ferber, P., Foltz, F., \& Pugliese, R. (2005). Computer-mediated communication in the Arizona legislature: Applying media richness theory to member and staff communication. State and Local Government Review, 37, 142-150.

Fountain, J. E. (2001). Building the virtual state: Information technology and institutional change. Washington, DC: Brookings Institution Press.

Garson, G. D. (2004). The promise of digital government In A. Pavlichev \& G. D. Garson (Eds.), Digital government: Principles and best practices (pp. 2-15). Hershey, PA: Idea Group Publishing.

Gelman, A., \& King, G. (1990). Estimating incumbency advantage without bias. American Journal of Political Science, 34, 1142-1164.

Gelman, A., \& Rubin, D. B. (1992). Inference from iterative simulation using multiple sequences. Statistical Science, 7, 434-455. 
Goodliffe, J. (2004). War chests as precautionary savings. Political Behavior, 26, 289-315.

Grier, K. B., \& Munger, M. C. (1993). Comparing interest group PAC contributions to House and Senate incumbents, 1980-1986. Journal of Politics, 55, 615-643.

Herrnson, P. S., Stokes-Brown, A. K., \& Hindman, M. (2007). Campaign politics and the digital divide: constituency characteristics, strategic considerations, and candidate internet use in state legislative elections. Political Research Quarterly, 60, 31-42.

Johnson, D. W. (2004). Congress online: Bridging the gap between citizens and their representatives. New York, NY: Routledge.

Kamarck, E. C. (2002). Political campaigning on the Internet: Business as usual? In E. C. Kamarck \& J. S. Nye, Jr. (Eds.), Governance.com: Democracy in the information age (pp. 81-103). Washington, DC: Brookings Institution Press.

King, G. (1991). Constituency service and incumbency advantage. British Journal of Political Science, 21, 119-128.

Levitt, S. D., \& Wolfram, C. D. (1997). Decomposing the sources of incumbency advantage in the U.S. House. Legislative Studies Quarterly, 22, 45-60.

Lieberman, R. C. (2002). Ideas, institutions, and political order: Explaining political change. American Political Science Review, 96, 697-712.

Lipinski, D. (2004). Congressional communication: Content and consequences. Ann Arbor: University of Michigan Press.

Mayhew, D. R. (1974). Congress: The electoral connection. New Haven, CT: Yale University Press.

Owen, D., Davis, R., \& Strickler, V. J. (1999). Congress and the Internet. Harvard International Journal of Press/Politics, 4(2), 10-29.

Page, S. E. (2006). Path dependence. Quarterly Journal of Political Science, 1, 87-115.

Pentland, A., Fletcher, R., \& Hasson, A. (2004). DakNet: Rethinking connectivity in developing nations. Computer, 37(1), 78-83.

Pierson, P. (2000). Increasing returns, path dependence, and the study of politics. American Political Science Review, 94, 251-267.

Pierson, P. (2004). Politics in time: History, institutions, and social analysis. Princeton, NJ: Princeton University Press.

Pitkin, H. F. (1967). The concept of representation. Berkeley: University of California Press.

Roscoe, T. (1999). The construction of the World Wide Web audience. Media, Culture \& Society, 21, 673-684.

Schaffner, B. F. (2006). Local news coverage and the incumbency advantage in the U.S. House. Legislative Studies Quarterly, 31, 491-511.

Shane, P. M. (2004). The electronic Federalist: The Internet and eclectic institutionalization of democratic legitimacy. In P. M. Shane (Ed.), Democracy online: The prospects for political renewal through the Internet (pp. 65-82). New York, NY: Routledge.

Sparrow, B. H. (2006). A research agenda for an institutional media. Political Communication, 23, $145-157$.

Spiegelhalter, D., Thomas, A., Best, N., \& Gilks, W. (1996). BUGS 0.5: Bayesian inference using Gibbs sampling manual (Version 2, Technical report). Cambridge, England: MRC Biostatistics Unit.

Stromer-Galley, J. (2000). On-line interaction and why candidates avoid it. Journal of Communication, 50, 111-132.

Suchman, M. C. (1995). Managing legitimacy: Strategic and institutional approaches. Academy of Management Review, 20, 571-610.

Tanner, M. A., \& Wong, W. H. (1987). The calculation of posterior distributions by data augmentation. Journal of the American Statistical Association, 82, 528-540.

Trier, S., \& Jackman, S. (2008). Democracy as a latent variable. American Journal of Political Science, 52, 201-217.

Xenos, M. A., \& Foot, K. A. (2005). Politics as usual, or politics unusual? Position taking and dialogue on campaign Websites in the 2002 U.S. elections. Journal of Communication, 55, 169-185. 


\section{Appendix: Coding Rules and Statistical Model}

This appendix contains a table with the detailed coding rules of each of our items and the statistical model written as a set of equations.

Item coding rules

\begin{tabular}{|c|c|c|}
\hline Item & Scale & Coding rule \\
\hline \multicolumn{3}{|l|}{ Issue factor items } \\
\hline National issues & $1-5$ & $\begin{array}{l}\text { To what extent does the site provide information about } \\
\text { major national issues (e.g., education, budget, taxes, } \\
\text { defense/foreign affairs, health care, workforce, } \\
\text { economy, energy, agriculture, transportation, trade, } \\
\text { Social Security, Medicare, etc.)? } 1 \text { = National issues } \\
\text { are only addressed through press releases in the press } \\
\text { release section (if a site has a press release section, it } \\
\text { will score at least a 1); } 2=\text { National issues are } \\
\text { addressed through a sparse issues section (less than } \\
5 \text { national [versus member or district/state] issues); } \\
3=\text { The issue section contains at least } 5 \text { national } \\
\text { issues that are addressed through a paragraph or } 2 \text { of } \\
\text { narrative OR through links to further information } \\
\text { (i.e., press releases); } 4=\text { The issue section contains } \\
\text { more than } 5 \text { national issues that are addressed } \\
\text { through a paragraph or } 2 \text { of narrative or links to } \\
\text { further information within the site (i.e., press } \\
\text { releases); } 5=\text { The issues section contains at least } \\
10 \text { national issues addressed through informative } \\
\text { narratives AND links to further information on } \\
\text { and/or off the site. (Recoded: } 1-3=0,4-5=1 \text { ) }\end{array}$ \\
\hline Member's issues & $0-1$ & $\begin{array}{l}\text { The site provides issue information or features (not } \\
\text { links to features off the site, but information on the } \\
\text { site) related to issues the member is active on. } \\
\text { To count as member issues, the issues must be } \\
\text { highlighted in the biography and more information } \\
\text { on the highlighted issues must be available in the } \\
\text { issues/legislation section. If there is no issues } \\
\text { section, there cannot be member's issues on the site. }\end{array}$ \\
\hline State/Local issues & $0-1$ & $\begin{array}{l}\text { The site provides issue information or features (not } \\
\text { general interest, but issue-related) related to issues of } \\
\text { specific interest to the district or state. If national } \\
\text { issues are addressed at the local level, it does not } \\
\text { count here. This is more for geniuinely local issues } \\
\text { like highways or location-specific issues (Yucca } \\
\text { Mountain, national parks in district/state, road } \\
\text { projects, etc.). }\end{array}$ \\
\hline
\end{tabular}


Appendix

(Continued)

\begin{tabular}{|c|c|c|}
\hline Item & Scale & Coding rule \\
\hline Vote rationales & $0-5$ & $\begin{array}{l}\text { To what extent does the site provide information about } \\
\text { why a member voted a certain way on certain } \\
\text { legislation? This information might be included in } \\
\text { the issues section or as a separate section (or not at } \\
\text { all). Press releases and e-newsletters do not count, } \\
\text { unless they're featured on the home page, since } \\
\text { we're looking for information that's easy to find and } \\
\text { access online. It ONLY counts where there is } \\
\text { reference to specific legislation (H.R. } 1234 \text { or a } \\
\text { specific bill title), how the member voted, AND the } \\
\text { member's reasons for voting that way. Discussing } \\
\text { bills the member introduced does not count as vote } \\
\text { rationale. } 1=\text { Vote rationales are addressed only } \\
\text { through press releases or features on the home page; } \\
2=\text { Some of the issues sections / write-ups contain } \\
\text { vote rationales; } 3=\text { Most of the issues sections } \\
\text { contain vote rationales; } 4=\text { All of the issues sections } \\
\text { contain vote rationales; } 5=\text { All of the issues sections } \\
\text { contain highlights of key votes and the member's } \\
\text { vote rationales. (Recoded: } 0=0,1-5=1 \text { ) }\end{array}$ \\
\hline Current events & $0-1$ & $\begin{array}{l}\text { Home page includes a feature(s) or highlight(s) on an } \\
\text { event or issue that is currently in the national news. } \\
\text { Excludes press releases and only counts if there is a } \\
\text { special feature (or link to a special feature) on Iraq, } \\
\text { immigration, Katrina/hurricanes, gas prices, etc. } \\
\text { Local issues count only if they are important enough } \\
\text { to have become national news. }\end{array}$ \\
\hline Content is current & $0-1$ & $\begin{array}{l}\text { MOST of the issue information addresses } \\
\text { legislation/issues from the 109th Congress } \\
\text { (evaluators will have to look up bill references on } \\
\text { Thomas). Most means more than half of the issues. }\end{array}$ \\
\hline Timeliness & $1-5$ & $\begin{array}{l}\text { How up to date is the site? } 1=\text { Everything on the site is } \\
\text { clearly old, even press releases; } 2=\text { Press releases } \\
\text { are up to date (within the last month), and everything } \\
\text { else is old; } 3=\text { Press releases are up to date, and } \\
\text { everything else is too generic to tell the age; } 4= \\
\text { Press releases and issues are up to date (press within } \\
\text { the last month and issues obviously from the } 109 \text { th } \\
\text { Congress); } 5=\text { Everything is clearly up to date, and } \\
\text { it is clear that the office makes an effort to include } \\
\text { timely information on the site. (Recoded: } 1-3=0 \text {, } \\
4-5=1 \text { ) }\end{array}$ \\
\hline
\end{tabular}


Appendix

(Continued)

\begin{tabular}{|c|c|c|}
\hline Item & Scale & Coding rule \\
\hline \multicolumn{3}{|c|}{ Constituent factor items } \\
\hline $\begin{array}{l}\text { Answers to } \\
\text { casework FAQs }\end{array}$ & $0-5$ & $\begin{array}{l}\text { To what extent does the site help constituents } \\
\text { understand what the office can do for them and how } \\
\text { to get answers to their questions? (This does not } \\
\text { have to be in the form of question and answer.) } 1= \\
\text { The site only has a contact my office for assistance } \\
\text { message; } 2=\text { In the services section, the site has a } \\
\text { contact my office for assistance message and links to } \\
\text { agency home pages or very basic information (a } \\
\text { couple of sentences); } 3=\text { In the services section, the } \\
\text { site provides limited guidance (e.g., a paragraph on } \\
\text { types of cases the office handles); } 4=\text { In the services } \\
\text { section, the site provides sections on more than } 4 \\
\text { types of casework services (e.g., passports, Social } \\
\text { Security, veterans' benefits, business assistance, } \\
\text { student loans, etc.) with extensive information } \\
\text { and/or links to specific information on agency Web } \\
\text { sites; } 5=\text { In the services section, the site provides } \\
\text { sections on more than } 4 \text { types of casework services } \\
\text { and incorporates links to specific agency pages } \\
\text { and/or contact information INCLUDING } \\
\text { information about local resources for assistance. } \\
\text { (Recoded: } 0-2=0,3-5=1 \text { ) }\end{array}$ \\
\hline $\begin{array}{l}\text { Guidance on } \\
\text { casework } \\
\text { initiation }\end{array}$ & $0-1$ & $\begin{array}{l}\text { The site clearly explains how and why a constituent } \\
\text { can initiate a casework request. Needs to give } \\
\text { constituents at least a bit of context about how the } \\
\text { office can help, what casework is, and/or how to } \\
\text { open a case. Just providing a form doesn't count. }\end{array}$ \\
\hline Casework form & $0-1$ & $\begin{array}{l}\text { The site provides a form (can be PDF) for constituents } \\
\text { to fill out to initiate a casework request. The privacy } \\
\text { release form is the same thing as a casework form. } \\
\text { It will usually be provided in PDF because it requires } \\
\text { a physical signature so the member can get personal } \\
\text { information about the case from the relevant agency. }\end{array}$ \\
\hline Agency links & $0-1$ & $\begin{array}{l}\text { The site provides links to agency Web sites in a section } \\
\text { other than the constituent services section (e.g., a } \\
\text { links or resources page). This is for links included in } \\
\text { another section. If they are included in the casework } \\
\text { section, it does not count for this. }\end{array}$ \\
\hline Link to FirstGov & $0-1$ & $\begin{array}{l}\text { The site includs a link to FirstGov (the federal } \\
\text { government portal). A link to FirstGov for Kids does } \\
\text { count. }\end{array}$ \\
\hline
\end{tabular}


Appendix

(Continued)

\begin{tabular}{|c|c|c|}
\hline Item & Scale & Coding rule \\
\hline $\begin{array}{l}\text { Internship } \\
\text { information }\end{array}$ & $0-1$ & $\begin{array}{l}\text { The site provides information on how to apply for an } \\
\text { internship (just a form, a sole reference to the office } \\
\text { having interns, or a contact my office to learn more } \\
\text { message does not count). }\end{array}$ \\
\hline $\begin{array}{l}\text { Academy } \\
\text { information }\end{array}$ & $0-1$ & $\begin{array}{l}\text { The site provides information on how to apply for an } \\
\text { academy nomination (just a form or reference or a } \\
\text { contact my office to learn more message does not } \\
\text { count; links to academy Web sites with some contex } \\
\text { do count). }\end{array}$ \\
\hline Flag information & $0-1$ & $\begin{array}{l}\text { The site provides information on how to order a flag } \\
\text { from the office (a contact my office message or flag } \\
\text { request form without context does not count). Must } \\
\text { include information about what the flags are and/or } \\
\text { why a constituent may want one. }\end{array}$ \\
\hline Grant information & $0-1$ & $\begin{array}{l}\text { The site provides information on how to get } \\
\text { government grants. Student loan information does } \\
\text { not count. }\end{array}$ \\
\hline $\begin{array}{l}\text { Information about } \\
\text { district resources }\end{array}$ & $0-1$ & $\begin{array}{l}\text { In the services section, the site includes information } \\
\text { about local resources for assistance (links in the } \\
\text { district/state section or a links page count only if } \\
\text { they are to services, not towns, sports venues, } \\
\text { educational institutions, etc.). Links must be to } \\
\text { services-places where the constituent can get help. } \\
\text { The best place for this to be included is in the } \\
\text { casework section, but OK if it's included in district } \\
\text { section, as long as it's to SERVICES. Links to state } \\
\text { and local government only count if they are to } \\
\text { specific agencies, versus the governor's office, the } \\
\text { state government portal, or municipal pages. }\end{array}$ \\
\hline \multicolumn{3}{|l|}{ Technology factor items } \\
\hline Video & $0-1$ & $\begin{array}{l}\text { The site provides video clips (welcome messages do } \\
\text { not count-think substance [floor speeches, } \\
\text { committee hearings, etc.]). }\end{array}$ \\
\hline Audio & $0-1$ & $\begin{array}{l}\text { The site provides audio clips (welcome messages do } \\
\text { not count-think substance [floor speeches, } \\
\text { committee hearings, etc.]). }\end{array}$ \\
\hline Text only & $0-1$ & $\begin{array}{l}\text { The site allows option for a text-only screen for faster } \\
\text { downloading. }\end{array}$ \\
\hline Blog & $0-1$ & $\begin{array}{l}\text { The site includes a blog (counts even if it's not a real } \\
\text { blog that accepts comments). }\end{array}$ \\
\hline RSS feed & $0-1$ & $\begin{array}{l}\text { The site includes an RSS feed (sometimes hard to } \\
\text { tell—when in doubt, don't include it). }\end{array}$ \\
\hline Podcast & $0-1$ & $\begin{array}{l}\text { The site includes a podcast (audio updates } \\
\text { automatically sent to subscribers). }\end{array}$ \\
\hline
\end{tabular}


Appendix

(Continued)

\begin{tabular}{|c|c|c|}
\hline Item & Scale & Coding rule \\
\hline Look and feel & $1-5$ & $\begin{array}{l}\text { What impression does the look and feel/design leave? } \\
1=\text { The look and feel looks like circa } 1996 \text { with lots } \\
\text { of scrolling, ugly colors, and clunky navigation; } 2= \\
\text { The look and feel is too cluttered, too sparse, and } \\
\text { generally uninviting; } 3=\text { The look and feel is OK, } \\
\text { not too uninviting, but not exactly inviting either; } \\
4=\text { The look and feel is inviting and professional; } \\
5=\text { The look and feel is in keeping with what you } \\
\text { expect from the better commercial Web sites. } \\
\text { (Recoded: } 1-3=0,4-5=1 \text { ) }\end{array}$ \\
\hline Navigation & $1-5$ & $\begin{array}{l}\text { How easy is it to move about the site? Navigation is } \\
\text { about movement through the site, and it includes link } \\
\text { text but not information location. This is about the } \\
\text { menus and links. Organization is about whether or } \\
\text { not information is where you would expect it to be. } \\
1 \text { = Navigation is dependent on back button and } \\
\text { home page (no navigation bar); } 2=\text { Navigation links } \\
\text { are confusing (language doesn't make it clear what } \\
\text { you'll find), navigation options are so abundant that } \\
\text { it's hard to find what you're looking for, navigation } \\
\text { changes on every page, and/or some of the main } \\
\text { navigation links go off site or to PDF files; } 3= \\
\text { Navigation may be cluttered, but it's clear what } \\
\text { you'll be getting at the other end; } 4=\text { It is easy to } \\
\text { navigate through the site and easy to understand } \\
\text { what you'll get when you click on a link; } 5= \\
\text { Navigation is clear and easy, and the site provides } \\
\text { additional navigation features on most pages (such } \\
\text { as links within text [e.g., links to bill text are } \\
\text { included on issue pages] or section- or page-specific } \\
\text { navigation tools that make navigation easier [e.g., } \\
\text { breadcrumbs or links to additional related } \\
\text { information]). (Recoded: } 1-3=0,4-5=1 \text { ) }\end{array}$ \\
\hline Readability & $1-5$ & $\begin{array}{l}\text { How easy is it to read the content of the site? This is } \\
\text { not about content, but about whether it's easy to scan } \\
\text { pages, whether there are bullets, headers, and clear } \\
\text { links; whether the contrast between the foreground } \\
\text { and background makes the text legible; and whether } \\
\text { there are short pages and paragraphs. A site where } \\
\text { you have to read or scroll down } 10 \text { screens on most } \\
\text { pages is not that readable. } 1=\text { On most pages, the } \\
\text { contrast between the text and the background or }\end{array}$ \\
\hline
\end{tabular}


Appendix

(Continued)

\begin{tabular}{ll}
\hline Item Scale & \multicolumn{1}{c}{ Coding rule } \\
\hline & changing fonts and font sizes make the pages \\
& difficult to read; $2=$ On many pages, the sheer \\
& volume of information (e.g., really long text or really \\
& long lists of links) makes the pages difficult to read; \\
& $3=$ Generally, the information on the site is easy to \\
& read; $4=$ Generally, the information on the site is \\
& written for the Web, with short paragraphs, bullets, \\
& headings, internal links, etc. that make it easy to read \\
& and scan through; $5=$ The information throughout \\
& the site is written for the Web. (Recoded: $1-3=0$, \\
& $4-5=1)$ \\
Organization is about whether or not information is & \\
& where you would expect it to be or whether you have \\
& to hunt around for it. Movement through the site is \\
& navigation. How well is the site organized? $1=$ The \\
& site appears thrown together with no thought, rhyme, \\
& or reason; $2=$ Some thought seemed to go into how \\
the site was organized, but it is difficult to figure out & the organization scheme and difficult to find the \\
information you're looking for; $3=$ The site is \\
organized well enough that you can usually find \\
what you're looking for with only one or two false \\
starts; $4=$ The site is organized well enough that \\
you can usually find what you're looking for within \\
three clicks (no false starts); $5=$ The site is \\
organized well enough that you can usually find \\
what you're looking for within three clicks AND \\
you usually have access to additional information \\
from other sections of the site (the site is \\
cross-referenced). (Recoded: $1-3=0,4-5=1$ )
\end{tabular}




\section{Issues 2007 Factor $\left(\eta_{1}\right)$ Equations}

$$
\begin{aligned}
\text { National Issues }_{2007, i} & \sim \operatorname{Bernoulli}\left(p_{1, i}\right) \\
p_{1, i} & =\Phi\left(\beta_{1}+1 \cdot \eta_{1, i}\right) \\
\text { Member Issues }_{2007, i} & \sim \operatorname{Bernoulli}\left(p_{2, i}\right) \\
p_{2, i} & =\Phi\left(\beta_{2}+\lambda_{\eta_{1,1}} \cdot \eta_{1, i}\right) \\
\text { State }_{\text {Local Issues }}^{2007, i} & \sim \operatorname{Bernoulli}\left(p_{3, i}\right) \\
p_{3, i} & =\Phi\left(\beta_{3}+\lambda_{\eta_{1,2}} \cdot \eta_{1, i}\right) \\
\text { Vote Rationales }_{2007, i} & \sim \operatorname{Bernoulli}\left(p_{4, i}\right) \\
p_{4, i} & =\Phi\left(\beta_{4}+\lambda_{\eta_{1,3}} \cdot \eta_{1, i}\right) \\
\text { Current Events }_{2007, i} & \sim \operatorname{Bernoulli}\left(p_{5, i}\right) \\
p_{5, i} & =\Phi\left(\beta_{5}+\lambda_{\eta_{1,4}} \cdot \eta_{1, i}\right) \\
\text { Issue Content Current }_{2007, i} & \sim \operatorname{Bernoulli}\left(p_{6, i}\right) \\
p_{6, i} & =\Phi\left(\beta_{6}+\lambda_{\eta_{1,5}} \cdot \eta_{1, i}\right) \\
\text { Timeliness }_{2007, i} & \sim \operatorname{Bernoulli}\left(p_{7, i}\right) \\
p_{7, i} & =\Phi\left(\beta_{7}+\lambda_{\eta_{1,6}} \cdot \eta_{1, i}\right)
\end{aligned}
$$

\section{Constituents 2007 Factor $\left(\eta_{2}\right)$ Equations}

$$
\begin{aligned}
& \text { Casework FAQs }_{2007, i} \sim \operatorname{Bernoulli}\left(p_{8, i}\right) \\
& p_{8, i}=\Phi\left(\beta_{8}+1 \cdot \eta_{2, i}\right) \\
& \text { Casework Initiation } 2007, i \sim \operatorname{Bernoulli}\left(p_{9, i}\right) \\
& p_{9, i}=\Phi\left(\beta_{9}+\lambda_{\eta_{2,1}} \cdot \eta_{2, i}\right) \\
& \text { Casework Form }_{2007, i} \sim \operatorname{Bernoulli}\left(p_{10, i}\right) \\
& p_{10, i}=\Phi\left(\beta_{1} 0+\lambda_{\eta_{2,2}} \cdot \eta_{2, i}\right) \\
& \text { Agency Links } 2007, i \sim \operatorname{Bernoulli}\left(p_{11, i}\right) \\
& p_{11, i}=\Phi\left(\beta_{1} 1+\lambda_{\eta_{2,3}} \cdot \eta_{2, i}\right) \\
& \text { FirstGov Link } 2007, i \sim \operatorname{Bernoulli}\left(p_{12, i}\right) \\
& p_{12, i}=\Phi\left(\beta_{1} 2+\lambda_{\eta_{2,4}} \cdot \eta_{2, i}\right) \\
& \left.\begin{array}{rl}
\text { Internship Info } 2007, i & \sim \operatorname{Bernoulli}\left(p_{13, i}\right) \\
p_{13, i} & =\Phi\left(\beta_{1} 3+\lambda_{\eta_{2,5}} \cdot \eta_{2, i}\right)
\end{array}\right\} 1 \leq i \leq N \\
& \text { Academy } \operatorname{Info}_{2007, i} \sim \operatorname{Bernoulli}\left(p_{14, i}\right) \\
& p_{14, i}=\Phi\left(\beta_{1} 4+\lambda_{\eta_{2,6}} \cdot \eta_{2, i}\right) \\
& \text { Flag Info } \operatorname{In07,i}_{2} \sim \operatorname{Bernoulli}\left(p_{15, i}\right) \\
& p_{15, i}=\Phi\left(\beta_{1} 5+\lambda_{\eta_{2,7}} \cdot \eta_{2, i}\right) \\
& \text { Grant } \operatorname{Info}_{2007, i} \sim \operatorname{Bernoulli}\left(p_{16, i}\right) \\
& p_{16, i}=\Phi\left(\beta_{1} 6+\lambda_{\eta_{2,8}} \cdot \eta_{2, i}\right) \\
& \text { District Resources }_{2007, i} \sim \operatorname{Bernoulli}\left(p_{17, i}\right) \\
& p_{17, i}=\Phi\left(\beta_{1} 7+\lambda_{\eta_{2,9}} \cdot \eta_{2, i}\right)
\end{aligned}
$$


Technology 2007 Factor $\left(\eta_{3}\right)$ Equations

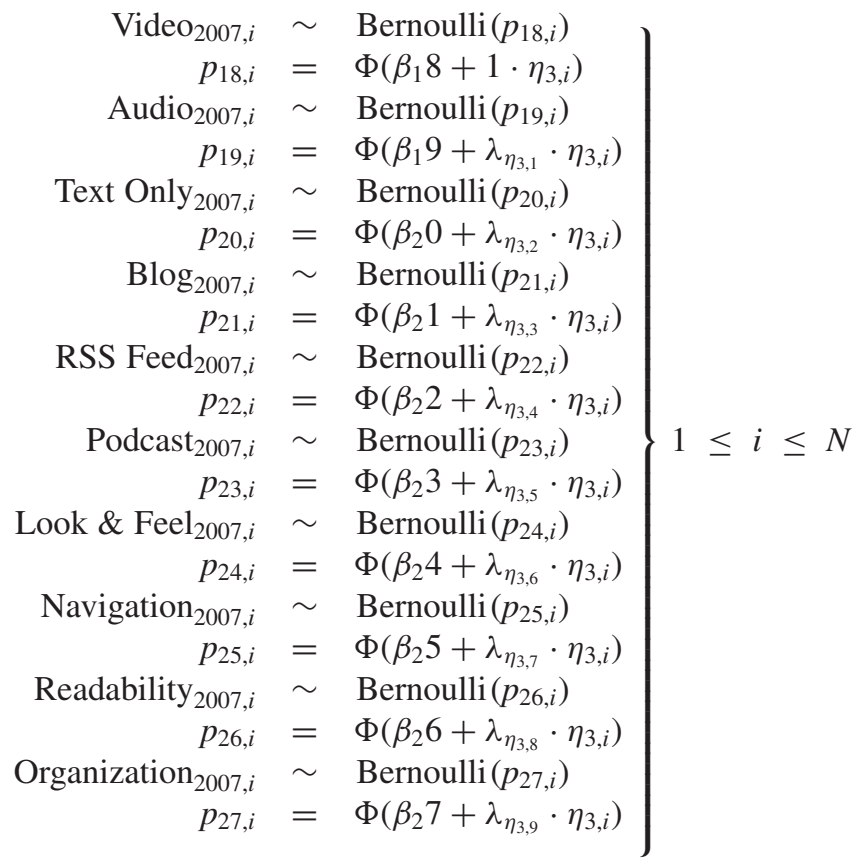

Issues 2006 Factor $\left(\theta_{1}\right)$ Equations

$$
\begin{aligned}
& \text { National Issues } 2006, i \sim \operatorname{Bernoulli}\left(p_{28, i}\right) \\
& p_{28, i}=\Phi\left(\beta_{2} 8+1 \cdot \theta_{1, i}\right) \\
& \text { Member Issues 2006,i } \sim \operatorname{Bernoulli}\left(p_{29, i}\right) \\
& p_{29, i}=\Phi\left(\beta_{2} 9+\lambda_{\theta_{1,1}} \cdot \theta_{1, i}\right) \\
& \text { State/Local Issues 2006,i } \sim \operatorname{Bernoulli}\left(p_{30, i}\right) \\
& p_{30, i}=\Phi\left(\beta_{3} 0+\lambda_{\theta_{1,2}} \cdot \theta_{1, i}\right) \\
& \text { Vote Rationales } 2006, i \sim \operatorname{Bernoulli}\left(p_{31, i}\right) \\
& \left.p_{31, i}=\Phi\left(\beta_{3} 1+\lambda_{\theta_{1,3}} \cdot \theta_{1, i}\right)\right\} 1 \leq i \leq N \\
& \text { Current Events 2006,i } \sim \operatorname{Bernoulli}\left(p_{32, i}\right) \\
& p_{32, i}=\Phi\left(\beta_{3} 2+\lambda_{\theta_{1,4}} \cdot \theta_{1, i}\right) \\
& \text { Issue Content Current 2006,i } \sim \operatorname{Bernoulli}\left(p_{33, i}\right) \\
& p_{33, i}=\Phi\left(\beta_{3} 3+\lambda_{\theta_{1,5}} \cdot \theta_{1, i}\right) \\
& \operatorname{Timeliness}_{2006, i} \sim \operatorname{Bernoulli}\left(p_{34, i}\right) \\
& p_{34, i}=\Phi\left(\beta_{3} 4+\lambda_{\theta_{1,6}} \cdot \theta_{1, i}\right)
\end{aligned}
$$




\section{Constituents 2006 Factor $\left(\theta_{2}\right)$ Equations}

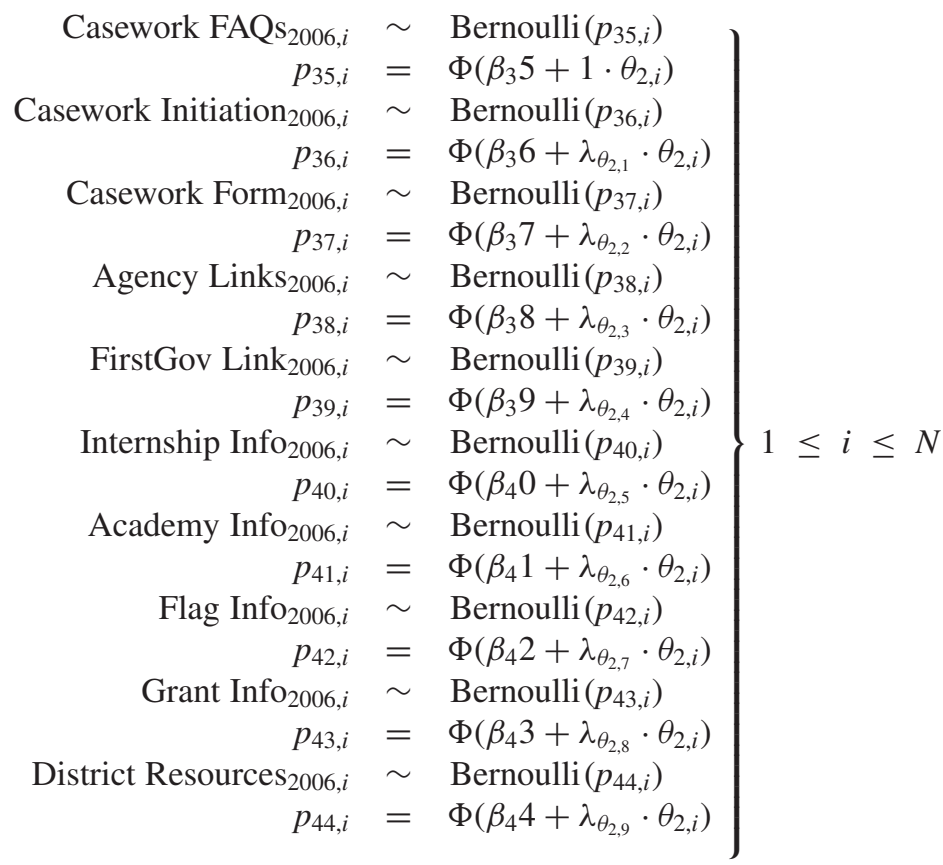

Technology 2006 Factor $\left(\theta_{3}\right)$ Equations

$$
\left.\begin{array}{rl}
\text { Video }_{2006, i} & \sim \operatorname{Bernoulli}\left(p_{45, i}\right) \\
p_{45, i} & =\Phi\left(\beta_{4} 5+1 \cdot \theta_{3, i}\right) \\
\text { Audio }_{2006, i} & \sim \operatorname{Bernoulli}\left(p_{46, i}\right) \\
p_{46, i} & =\Phi\left(\beta_{4} 6+\lambda_{\theta_{3,1}} \cdot \theta_{3, i}\right) \\
\text { Text Only }_{2006, i} & \sim \operatorname{Bernoulli}\left(p_{47, i}\right) \\
p_{47, i} & =\Phi\left(\beta_{4} 7+\lambda_{\theta_{3,2}} \cdot \theta_{3, i}\right) \\
\operatorname{Blog}_{2006, i} & \sim \operatorname{Bernoulli}\left(p_{48, i}\right) \\
p_{48, i} & =\Phi\left(\beta_{4} 8+\lambda_{\theta_{3,3}} \cdot \theta_{3, i}\right) \\
\operatorname{RSS~Feed~}_{2006, i} & \sim \operatorname{Bernoulli}\left(p_{49, i}\right) \\
p_{49, i} & =\Phi\left(\beta_{4} 9+\lambda_{\theta_{3,4}} \cdot \theta_{3, i}\right) \\
\text { Podcast }_{2006, i} & \sim \operatorname{Bernoulli}\left(p_{50, i}\right) \\
p_{50, i} & =\Phi\left(\beta_{5} 0+\lambda_{\theta_{3,5}} \cdot \theta_{3, i}\right) \\
\text { Look \& Feel }_{2006, i} & \sim \operatorname{Bernoulli}\left(p_{51, i}\right) \\
p_{51, i} & =\Phi\left(\beta_{5} 1+\lambda_{\theta_{3,6}} \cdot \theta_{3, i}\right) \\
\text { Navigation }_{2006, i} & \sim \operatorname{Bernoulli}\left(p_{52, i}\right) \\
p_{52, i} & =\Phi\left(\beta_{5} 2+\lambda_{\theta_{3,7}} \cdot \theta_{3, i}\right) \\
\text { Readability }_{2006, i} & \sim \operatorname{Bernoulli}\left(p_{53, i}\right) \\
p_{53, i} & =\Phi\left(\beta_{5} 3+\lambda_{\theta_{3,8}} \cdot \theta_{3, i}\right) \\
\text { Organization }_{2006, i} & \sim \operatorname{Bernoulli}\left(p_{54, i}\right) \\
p_{54, i} & =\Phi\left(\beta_{5} 4+\lambda_{\theta_{3,9}} \cdot \theta_{3, i}\right)
\end{array}\right\} \leq
$$


Prior Distributions

$$
\begin{aligned}
& \begin{array}{l}
\boldsymbol{\theta}_{\mathbf{i}} \sim \operatorname{MVN}\left([0,0,0]^{\prime}, \Sigma_{\theta}^{-1}\right) \\
\eta_{\mathbf{i}} \sim \operatorname{MVN}\left(\left[\mu_{\eta_{1, i}}, \mu_{\eta_{2, i}}, \mu_{\eta_{3, i}}\right]^{\prime}, \Sigma_{\eta}^{-1}\right)
\end{array} \\
& \left.\mu_{\eta_{1, i}}=\gamma_{\theta_{1,1}} \cdot \theta_{1, i}+\gamma_{\theta_{2,1}} \cdot \theta_{2, i}+\gamma_{\theta_{3,1}} \cdot \theta_{3, i}\right\} 1 \leq i \leq N \\
& \mu_{\eta_{2, i}}=\gamma_{\theta_{1,2}} \cdot \theta_{1, i}+\gamma_{\theta_{2,2}} \cdot \theta_{2, i}+\gamma_{\theta_{3,2}} \cdot \theta_{3, i} \\
& \mu_{\eta_{3, i}}=\gamma_{\theta_{1,3}} \cdot \theta_{1, i}+\gamma_{\theta_{2,3}} \cdot \theta_{2, i}+\gamma_{\theta_{3,3}} \cdot \theta_{3, i} \\
& \boldsymbol{\Sigma}_{\eta} \sim \operatorname{Wishart}_{3}\left(\mathbf{I}_{3}, 4\right) \\
& \boldsymbol{\Sigma}_{\boldsymbol{\theta}} \sim \operatorname{Wishart}_{3}\left(\mathbf{I}_{3}, 4\right) \\
& \left.\begin{array}{l}
\lambda_{\eta_{1, m}} \sim \operatorname{Uniform}(0,2) \\
\lambda_{\theta_{1, m}} \sim \operatorname{Uniform}(0,2)
\end{array}\right\} 1 \leq m \leq 6 \\
& \lambda_{\eta_{2, m}} \sim \operatorname{Uniform}(0,2) \\
& \lambda_{\theta_{2, m}} \sim \operatorname{Uniform}(0,2) \\
& \left.\lambda_{\eta_{3, m}} \sim \operatorname{Uniform}(0,2)\right\} 1 \leq m \leq 9 \\
& \lambda_{\theta_{3, m}} \sim \operatorname{Uniform}(0,2) \\
& \left.\beta_{m} \sim \phi(0,1,000)\right\} 1 \leq m \leq 54 \\
& \gamma_{\theta_{1, m}} \sim \phi(0,1,000) \\
& \gamma_{\theta_{2, m}} \sim \phi(0,1,000)
\end{aligned}
$$

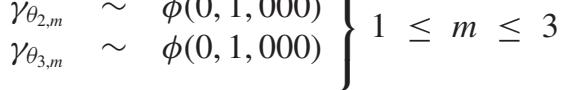

